\title{
Caracterização dos contaminantes do minério de ferro do depósito mineral da Serra do Sapo, Conceição do Mato Dentro, Minas Gerais
}

Characterization of the contaminants in the Serra do Sapo iron ore deposit, Conceição do Mato Dentro, Minas Gerais, Brazil

\author{
Fernando Prudencio Morais ${ }^{1}$ (D), Rosaline Cristina Figueiredo e Silva ${ }^{2}$ (D), \\ Carlos Alberto Rosiére ${ }^{2}$ (D) Geraldo Sarquis Dias $^{3}$ (D) \\ ${ }^{1}$ Universidade Federal de Minas Gerais - UFMG, Instituto de Geociências - IG, Programa de Pós-Graduação, Av. Antônio \\ Carlos, 6.627, Sala 3046, Caixa Postal 719, CEP 31270-901, Pampulha, Belo Horizonte, MG, BR (fernando.pmlins@gmail.com) \\ UFMG, IG, Belo Horizonte, MG, BR (rosalinecris@yahoo.com.br; crosiere@gmail.com) \\ ${ }^{3}$ Anglo American, Projeto Minas-Rio, Conceição do Mato Dentro, MG, BR (geraldo.dias@angloamerican.com)
}

Recebido em 6 de agosto de 2018; aceito em 16 de dezembro de 2019.

\begin{abstract}
Resumo
Os itabiritos do depósito mineral da Serra do Sapo estão localizados na região da Serra do Espinhaço Meridional e são descritos como parte da Formação Serra do Sapo, unidade superior do Grupo Serra da Serpentina, e estão sobrepostos aos xistos e aos filitos da Formação Meloso. Formações ferríferas com alto teor de Al e P ocorrem no contato com metassedimentos da unidade basal. Esses contatos são transicionais e geram uma rocha bandada, com níveis milimétricos a centimétricos contendo grande concentração de óxido de ferro. Essa litologia tem textura sedosa e ocorre sempre decomposta, sendo descrita como hematita-quartzo-mica xistos ou classificada como itabirito com alto teor de contaminantes (IFX). A classificação dos itabiritos é feita de acordo com o grau de decomposição intempérica da rocha. Formações ferríferas bandadas classificadas como itabiritos (IT), rocha sã, e que também apresentam altos teores de P como contaminante, são classificadas como itabirito com alto teor de fósforo (ITX). Estudos petrográficos identificaram muscovita, clorita e gibbsita como as principais fontes de $\mathrm{Al}$ para as amostras de IFX. Os altos teores de $\mathrm{Al}_{2} \mathrm{O}_{3}$ e $\mathrm{P}_{2} \mathrm{O}_{5}$ desses litotipos também são explicados pelo processo de formação supergênica, em que o espaço dos minerais lixiviados é preenchido por clorita e gibbsita. Para o ITX, os altos teores de P estão relacionados com minerais de apatita que ocorrem com maior frequência nesse litotipo. Dados geoquímicos de rocha total, quando normalizados ao Pos-Archean Australian Shale (PAAS), mostram que as amostras de IFX são enriquecidas em elementos terras raras leves (ETRL) se comparadas aos outros itabiritos. Essas amostras também são enriquecidas em elementos móveis como Ba e Sr. Isso indica que o enriquecimento é em razão da mobilidade dos ETRL em um ambiente intemperizado sem elementos terras raras pesados (ETRP).
\end{abstract}

Palavras-chave: Formação ferrífera; Serra do Sapo; Geoquímica.

\begin{abstract}
The itabirites of Serra do Sapo ore deposit are located in the Serra do Espinhaço region and are described as part of the Serra do Sapo Formation, the upper unit of the Serra da Serpentina Group, superposed to the schists and phyllites of the Meloso Formation. Iron formations with a high content of aluminum and phosphorus occur in contact with the schists of the basal unit. These contacts are transitional and generate a rock with millimeter to centimeter levels containing high iron oxide concentration. This lithology has a silky texture and always occurs decomposed, being described as hematite-quartz-mica schists or classified as Itabirite with high content of contaminants (IFX). The classification of itabirites is made according to the degree of weathering of the rock. Banded iron formations classified as Itabirites (IT) that also present high levels of phosphorus as contaminants; are classified as Itabirite with high phosphorus content (ITX). Petrographic studies identified muscovite, chlorite and gibbsite as the main sources of aluminum for IFX samples. The high levels of $\mathrm{Al}_{2} \mathrm{O}_{3}$ and $\mathrm{P}_{2} \mathrm{O}_{5}$ in these lithotypes are also explained by the supergenic formation process, where the space of the leached minerals is filled by chlorite and gibbsite. For ITX the high levels of phosphorus are related to apatite minerals that occur more frequently in this lithotype. Geochemical data shows that IFX samples, when normalized to PAAS, are enriched in LREE compared to the other itabirites. These samples are also enriched in mobile elements such as Ba and Sr. This indicates that the enrichment is due to the mobility of the LREE in a weathered environment without HREE.
\end{abstract}

Keywords: Iron Formations; Serra do Sapo; Geochemistry. 


\section{INTRODUÇÃO}

A Serra do Sapo, localizada entre os municípios de Conceição do Mato Dentro e Alvorada de Minas, na região central do estado de Minas Gerais, está inserida na borda leste da Serra do Espinhaço Meridional. Essa região compreende as principais ocorrências de formação ferrífera conhecidas na Serra do Espinhaço (Knauer, 2007), abrangendo os grupos São José (Rolim, 2016) e Serra da Serpentina (Almeida Abreu, 1989; Zacchi, 2010; Chemale et al., 2012; Dossin et al., 1985; Grossi-Sad e Magalhães, 1989; Almeida-Abreu et al., 1988; Rolim e Rosière, 2011).

Neste trabalho, serão discutidos os estudos petrográficos e geoquímicos de rocha total realizados nas amostras de testemunho de sondagem e afloramento que foram selecionadas de acordo com os altos teores de $\mathrm{Al}$ e $\mathrm{P}$. O propósito deste trabalho foi identificar as formas em que o $\mathrm{Pe} \mathrm{o} \mathrm{Al}_{2} \mathrm{O}_{3}$ ocorrem em associação com minério de ferro desse depósito mineral, além de verificar se houve alguma contribuição hidrotermal durante enriquecimento em $\mathrm{Fe}$ dos itabiritos com o intuito de facilitar o entendimento de trabalhos de classificação metalúrgica voltados para o processo de beneficiamento.

O P apresenta efeito indesejável no ferro gusa e aço causando o aparecimento de fissuras e a fragilidade a frio. A quantidade desse elemento principalmente no aço está diretamente ligada ao teor presente no minério de origem. A remoção de $\mathrm{Al}$ também é desejável, podendo tornar viável a exploração de jazidas com altos teores desses elementos.

\section{GEOLOGIA E CARACTERIZAÇÃO DOS ITABIRITOS}

A Serra do Espinhaço (Eschwege, 1822) consiste em uma faixa orogênica pré-cambriana que se alonga aproximadamente $1.200 \mathrm{~km}$ na direção N-S entre as regiões de Belo Horizonte e o estado da Bahia. Chemale et al. (2011) descrevem a denominação utilizada para a cordilheira considerando a área de ocorrência para seus diferentes segmentos:

1. Espinhaço Meridional, estendendo-se de Belo Horizonte até a região de Olhos D’Água, Minas Gerais;

2. Serra do Cabral, incluindo a Serra da Água Fria, em Minas Gerais;

3. Espinhaço Setentrional, que se inicia na altura do paralelo $17^{\circ} 30^{\prime} \mathrm{S}$, em Minas Gerais, onde a serra ocorre separada e deslocada por aproximadamente $30 \mathrm{~km} \mathrm{na}$ direção NNE da parte meridional, com prolongamento contínuo do flanco oriental até o Estado da Bahia;

4. Chapada Diamantina, distribuindo-se inteiramente na porção centro-oriental da Bahia.

O depósito mineral da Serra do Sapo (Figura 1) é formado por um conjunto de rochas metassedimentares compostas por quartzitos, filitos, xistos, itabiritos e rochas carbonáticas.
A evolução geológica da região foi acompanhada pela geração de rochas ígneas vulcânicas e plutônicas.

As rochas do Complexo Basal são formadas por ortognaisses que ocorrem por toda a borda leste da Serra do Sapo em terrenos com suave topografia e afloramentos de corte de estrada onde as rochas ocorrem decompostas, com coloração rosa, granulação fina contendo níveis brancos, argilosos de material caulinítico. É possível observar a presença de porfiroclastos de quartzo com no máximo $3 \mathrm{~cm}$ de diâmetro inseridos em uma suave foliação da rocha. Essa litologia faz contato brusco com as rochas intrusivas máficas da região, além dos xistos e dos filitos da base da Formação Meloso.

Nos furos de sondagem, essas rochas são descritas como muscovita-biotita gnaisses, com granulação média, textura granoblástica contendo quartzo e feldspato com aproximadamente $1 \mathrm{~cm}$ de diâmetro e foliação bem definida. Os veios de quartzo ocorrem dispostos aleatoriamente, assim como níveis com presença de clorita concordante à foliação.

Sobrepostos aos gnaisses ocorrem rochas metassedimentares da Formação Meloso, predominantemente meta-argilosos de granulação fina com intercalação de quartzitos que afloram tanto na borda leste quanto na borda oeste da Serra do Sapo. Os filitos, cor cinza, fazem contato brusco com as rochas do Complexo Basal, ocorrem com textura sedosa e, quando decompostos, formam um material extremamente argiloso. Na borda oeste do depósito é possível observar afloramentos de filitos com presença de cristais milimétricos a centimétricos, euédricos de magnetita. Dentro da jazida esses afloramentos ocorrem com até $15 \mathrm{~m}$ de espessura.

Filitos grafitosos, cor cinza-escuro a negro, ocorrem de forma descontínua na região leste da serra. Esses filitos têm granulação fina e foliação ondulada marcada por níveis milimétricos de material sericítico concordante à foliação da rocha.

Sobre os filitos ocorrem níveis métricos a decimétricos de quartzitos com cor variando de vermelho a cinza, sendo geralmente micáceos com sericita definindo planos de foliação da rocha.

No contato com a formação ferrífera da Formação Serra do Sapo ocorrem os xistos da Formação Meloso, geralmente intemperizados na forma de saprolitos total ou parcialmente decompostos, de cor amarelo a vermelho, contendo cristais de quartzo e xistosidade marcada pela presença de muscovita e sericita. Esses xistos são localmente crenulados e fazem contato transicional com a mineralização ferrífera, gerando níveis de minerais de ferro intercalados com nível de argila contendo teores em $\mathrm{Fe}$ em muitos casos superiores aos itabiritos.

As formações ferríferas bandadas (FFB) da Serra do Sapo correspondem a itabiritos e são classificadas de acordo com o grau de intemperismo e compacidade da rocha (Figura 2). A classificação para o minério de baixo teor divide-se em itabirito friável (IF); itabirito semifriável (ISF) e itabirito (IT). 
O IF é uma rocha decomposta, cuja cor varia de cinza a cinza-escuro, formada por minerais desagregados decorrentes de um estágio final de intemperismo. Em geral, essa classe possui as maiores concentrações de Fe entre os itabiritos. O ISF é uma rocha estruturada em um estágio médio de intemperismo, podendo ser facilmente desagregada. Essa classe possui bandamento marcado por níveis decimétricos a centimétricos de hematita. Nos afloramentos, o processo de intemperismo é marcado primeiro pela lixiviação do quartzo e pela presença de muscovita entre os níveis de hematita.

A rocha sã é classificada como IT, formada de bandamento marcado pela alternância de níveis milimétricos a centimétricos de hematita e quartzo. Em algumas amostras é possível observar a presença de níveis milimétricos de clorita concordantes à foliação.

Os minérios com teores de Fe acima de 60\% (Figura 3) ocorrem no topo da camada onde a rocha fica enriquecida em minerais de ferro e pobre em quartzo. Esses litotipos também ocorrem na borda leste da serra por meio de corpos métricos a decamétricos podendo estar associados a falhamentos. Em alguns casos é possível observar um bandamento milimétrico e veios de quartzo concordantes ou discordantes à foliação da rocha. Essas litologias ocorrem com cor cinza-escura a cinza-azulada, e assim como os itabiritos mineralizados, são divididas de acordo com o seu grau de intemperismo e denominadas hematita friável ou mole (HM), em que os minerais que compõem essa rocha ocorrem desagregados em alto grau de intemperismo, e hematita compacta ou dura (HD), em geral na base dos itabiritos onde a rocha ocorre estruturada e fresca.

Formações ferríferas com alto de teor de AL e P ocorrem no contato com os xistos da unidade basal (Figura 4). Esses contatos são transicionais e geram uma rocha bandada, com níveis milimétricos a centimétricos contendo grande concentração de minerais de ferro, principalmente hematita, e níveis milimétricos a centimétricos de argila cuja cor varia de amarelo à cinza-escuro. Essa litologia tem textura sedosa e ocorre sempre decomposta, sendo descrita como hematita-quartzo-mica xistos ou classificada como itabirito com alto teor de contaminantes (IFX).
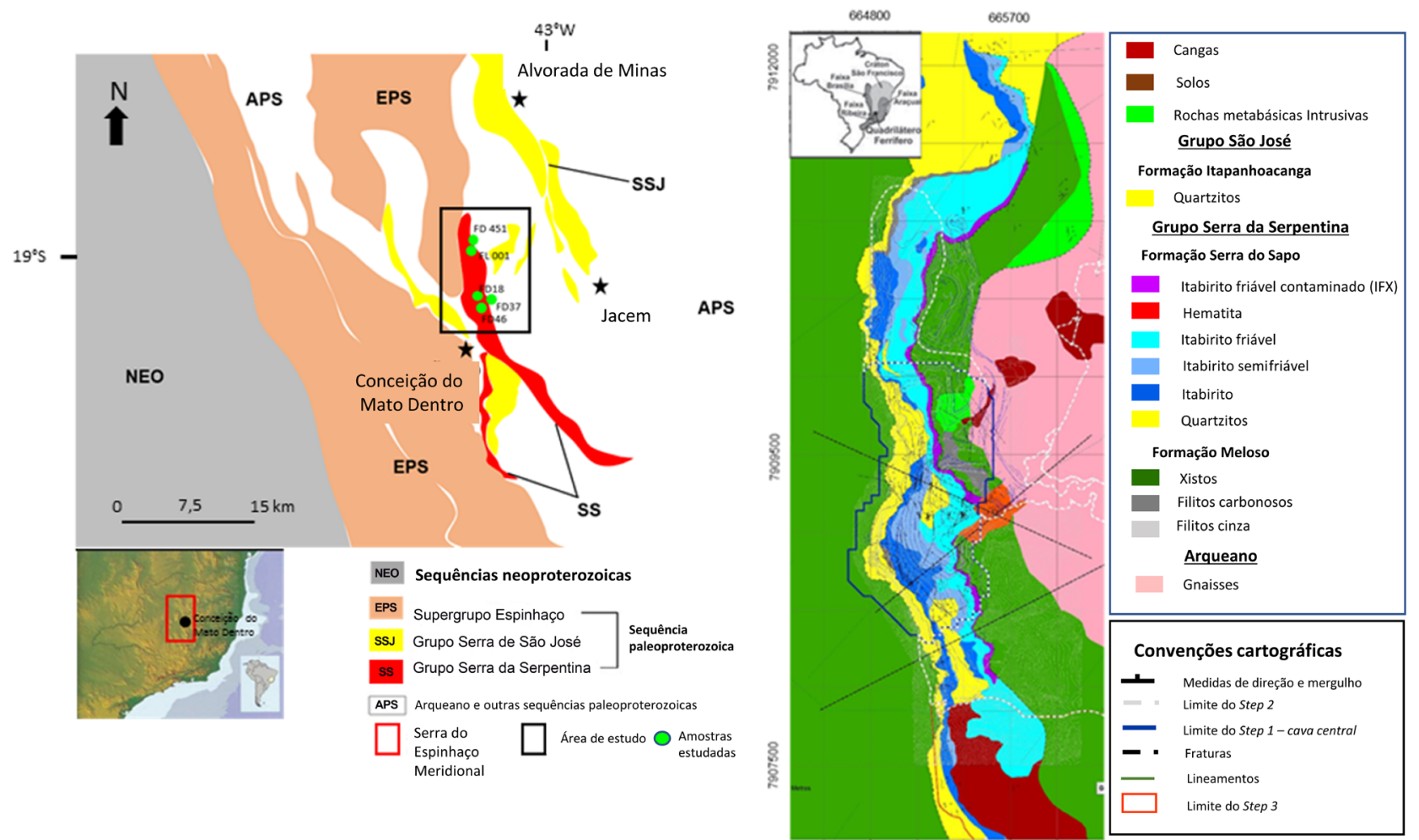

APS: ortognaisses e granitos de idade Arqueana; EPS: rochas do Supergrupo Espinhaço Meridional; SSJ: Grupo São José; SS: Grupo Serra da Serpentina; NEO: sequências neoproterozoicas.

Figura 1. À esquerda, mapa contextualizando as principais unidades aflorantes da borda leste da Serra do Espinhaço Meridional (modificado de Rolim et al., 2016), com a localização das amostras coletadas. À direita, mapa geológico das áreas principais de operação da mina, Step 1 e Step 2, mostrando a distribuição das litologias do Grupo Serra da Serpentina e da Formação Serra do Sapo com a classificação utilizada para os itabiritos. Projeção UTM, Datum sad 69 23S (Lobato et al., 2005). 

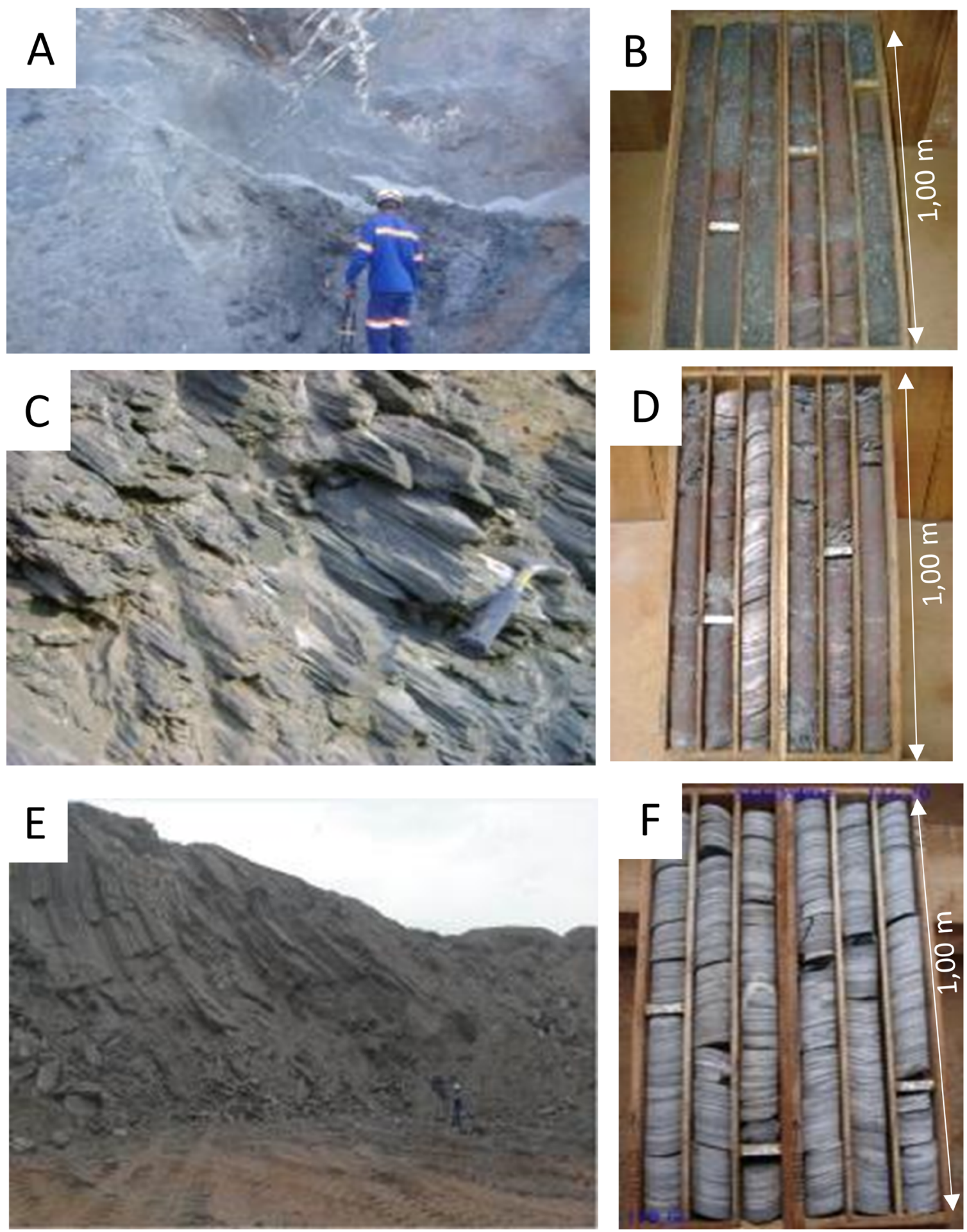

Figura 2. Fotos das três principais classes dos itabiritos de acordo com o grau de intemperismo das rochas nos afloramentos e no testemunho de sondagem. (A) Afloramento de itabirito friável, com presença centimétrica de veio de quartzo; (B) testemunho de itabirito friável mostrando o alto grau de decomposição supergênica da rocha; (C) afloramento de itabirito semi-friável em corte de estrada indicando o ângulo de foliação das rochas; (D) testemunho de sondagem mostrando a estruturação do itabirito semifriável; (E) itabirito estruturado, indicando o aumento do ângulo de foliação em algumas regiões da mina; $(F)$ foto do testemunho de sondagem do itabirito mostrando a forte estruturação da rocha e as alternâncias centimétricas dos níveis de quartzo e hematita. 


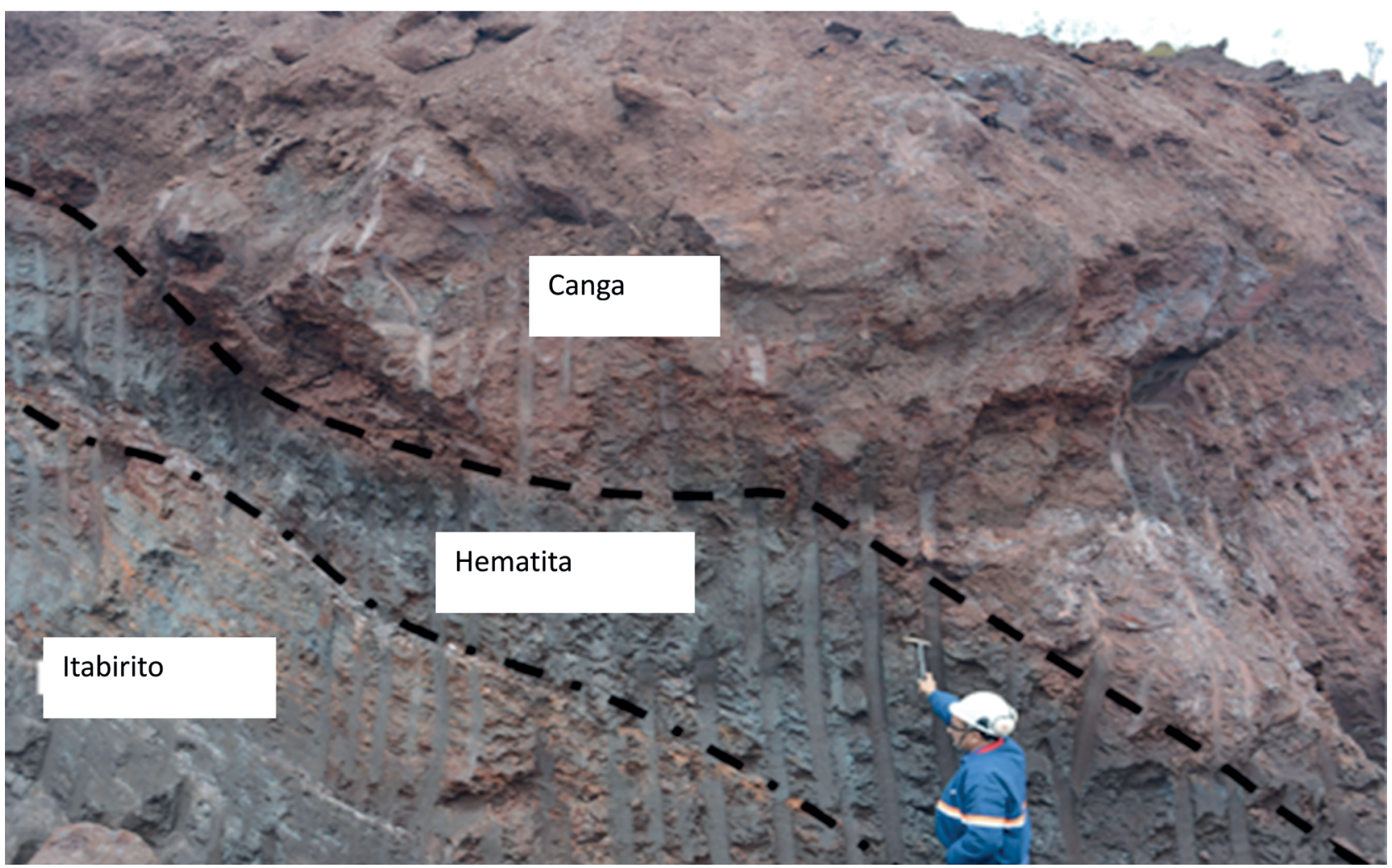

Figura 3. Afloramento de hematita friável (HM) no contato com o itabirito na base e o capeamento laterítico (canga).

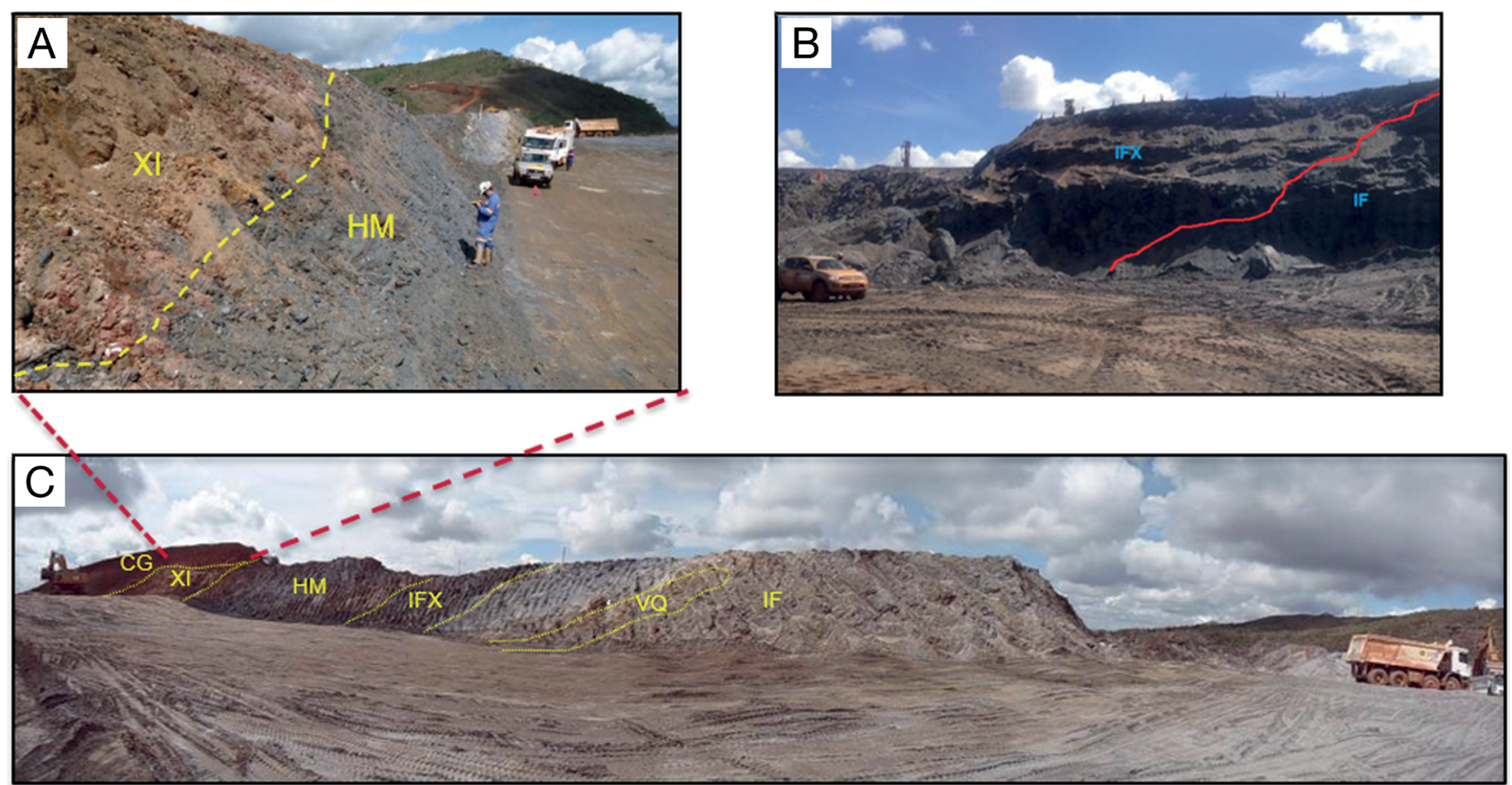

XI: xisto; HM: hematite; IFX: itabiritos com alto teor de contaminantes; IF: itabiritos; CG: canga não mineralizada; VQ: veio de quartzo.

Figura 4. Diferentes formas de ocorrência dos itabiritos com alto teor de contaminantes na região da mina. (A) Foto mostrando o contato entre o xisto da unidade basal e o itabirito com alto teor de contaminantes; (B e C) itabirito com alto teor de contaminantes ocorrendo em contatos gradacionais com a canga não mineralizada e os itabiritos; também ocorrem níveis de hematita e passagem de veio de quartzo no itabirito. 
Itabiritos previamente classificados como ISF (Tabela 1) contendo teores elevados de P na sua composição também são classificados como IFX, assim como itabiritos classificados como IT que também apresentam altos teores de P. Essas litologias ocorrem cortadas por veio de quartzo que podem estar concordantes ou discordantes à foliação da rocha.

Rochas metavulcânicas ocorrem na forma de sills, têm cor verde, granulação fina, foliação com mergulho de $37^{\circ}$ para $\mathrm{NE}$ que com espessuras métricas podem ser observadas tanto no topo como na base da sequência estratigráfica. O contato dessa litologia com as demais rochas da Formação Serra do Sapo é brusco, e próximo à superfície formam saprolitos argilosos de cor amarelo a ocre. No contato com a mineralização podem gerar níveis métricos de IFX. O topo da sequência estratigráfica é formado por afloramentos que ocorrem de maneira descontínua, apenas possível de ser observado em testemunhos de sondagem da região central e norte da jazida. A litologia que define essa unidade corresponde a dolomito de cor rosa e granulação fina que ocorre cortado por vênulas brancas de quartzo e calcita, podendo conter minerais de ferro remobilizados e níveis milimétricos de minerais micáceos. Na sondagem realizada dentro dos limites do depósito mineral da Serra do Sapo, essa litologia ocorre em intervalos de espessura métrica a poucas dezenas de metros. Veios de quartzo ocorrem cortando todas as litologias do depósito, em geral discordantes à foliação da rocha marcando os níveis de falhamento e faturamento. Nos furos de sondagem é possível observar a presença de cristais euédricos de pirita e magnetita associados aos veios do Complexo Basal. Nos itabiritos podem ocorrer veios de

Tabela 1. Código utilizado para nomear as diferentes variações dos itabiritos.

\begin{tabular}{lc}
\hline Código & Litotipos \\
\hline IF & Itabirito friável \\
IT & Itabirito \\
ITX & Itabirito com alto teor de fósforo \\
ISF & Itabirito semi-friável \\
IFX & Itabirito com alto teor de contaminantes \\
HM & Hematita friável \\
\hline
\end{tabular}

quartzo concordantes à foliação contendo cristais de hematita e mica branca, e quando associados a dolomitos, ocorrem com presença de minerais micáceos e carbonáticos. Grandes afloramentos de quartzo rugoso, contendo cristais de hematita e buracos de até $3,5 \mathrm{~cm}$ de diâmetro que marcam a presença de cristais ou seixos e níveis brechados com presença de Mn, estão presentes na porção norte da jazida.

\section{METODOLOGIA}

A metodologia de estudo se dividiu em amostragem de campo, estudos petrográficos e análise qualitativa dos minerais acessórios por meio de microscopia eletrônica e geoquímica de rocha total. A etapa de campo foi realizada no município de Conceição do Mato Dentro, e foram selecionados quatro furos de sondagem e uma amostra de frente de lavra para confecção de lâminas petrográficas. Essas amostras foram selecionadas por estarem localizadas em regiões da jazida que apresentaram teores elevados de $\mathrm{P}$ e $\mathrm{Al}$ na mineralização (Tabela 2).

A partir da seleção das amostras de minério mostradas na Tabela 2, foram confeccionadas mais 30 lâminas delgadas polidas de diferentes litologias do depósito, descritas em microscópio de luz transmitida e refletida LEICA, modelo DM2500P, no Laboratório de Metalogenia do Centro de Pesquisas Professor Manoel Teixeira da Costa (CPMTC), com ocular de 10X e objetivas de 2,5X, 5X,10X, 20X e $50 \mathrm{X}$. As análises petrográficas foram ilustradas por fotomicrografias em câmera LEICA, modelo DFC295.

Amostras descritas na petrografia foram selecionadas e analisadas no Quanta 3D Dual FIB do Centro de Microscopia Eletrônica da Universidade Federal de Minas Gerais (UFMG) por apresentarem quantidades significativas de minerais acessórios associados às formações ferríferas do depósito mineral da Serra do Sapo.

Dados de geoquímica de rocha total foram obtidos na Bureau Veritas Commodities Canada Ltd., onde foram analisadas dez amostras pelos métodos de análise quantitativa inductively coupled plasma emission spectrometry (ICPS-ES) e inductively coupled plasma mass spectrometry (ICP-MS), e digestão de $0,5 \mathrm{~g}$ de rocha pulverizada em água régia a

Tabela 2. As amostras e os furos de sonda em que foram descritas e coletadas as amostras.

\begin{tabular}{|c|c|c|c|c|c|c|}
\hline \multirow{2}{*}{ Furo } & \multirow{2}{*}{ Lâmina } & \multicolumn{3}{|c|}{ Localização } & \multirow{2}{*}{ Litologia } & \multirow{2}{*}{ Profundidade (m) } \\
\hline & & $x$ & $\mathrm{Y}$ & Z & & \\
\hline SEFDSP 37 & FD37-100,52 a 100,60 & 668249 & 7904373 & 702 & & 100,52 \\
\hline SEFDSP 18 & FD18-89,25 a 89,35 & 667807 & 7904377 & 789 & & 89,25 \\
\hline SEFDSP 46 & FD46-201,85 a 202,01 & 668003 & 7904198 & 748 & & 201,85 \\
\hline FL 001 & FL001 & 665249 & 7908877 & 865 & & Frente de lavra \\
\hline SEFDSP 37 & FD37-128,25 a 128,39 & 668249 & 7904373 & 702 & & 128,25 \\
\hline
\end{tabular}


temperatura de $90^{\circ} \mathrm{C}$ durante 2,5 horas, sendo estes os principais métodos quantitativos que fornecem dados adequados para traçar diagramas de classificação de rocha total e estudos de relação entre elementos químicos.

\section{PETROGRAFIA E MINERALOGIA}

De acordo com as descrições petrográficas, os óxidos de ferro foram classificados como descrito na Tabela 3.

As rochas analisadas ricas em ferro são constituídas de IFX e itabiritos com alto teor de fósforo (ITX). Os principais minerais constituintes das rochas são hematita, martita, kenomagnetita e quartzo (Tabela 3). Ocasionalmente ocorrem minerais como turmalina, gibbsita, muscovita e apatita, podendo estar presente principalmente nas amostras de IFX.

Microscopicamente, o IFX (Figura 5) consiste em uma rocha bandada marcada pela alternância das porções ricas em minerais micáceos e níveis milimétricos a centimétricos de minerais opacos. A textura da rocha é granoblástica marcada pela orientação dos minerais que refletem a foliação ondulante da rocha. As bandas de minerais transparentes são essencialmente compostas de mica branca, contendo cristais aciculares e placoides com granulação variando de 0,05 a $1,00 \mathrm{~mm}$ com presença de minerais opacos entre os contatos. As micas ocorrem como minerais alongados, por vezes dispersos, orientados segundo a foliação da rocha. As bandas de minerais opacos compõem-se essencialmente de cristais de hematita lamelar e microlamelar orientados e paralelos ao bandamento e à xistosidade da rocha, fazendo contato reto entre si com granulação variando de 0,01 a $0,50 \mathrm{~mm}$. Espaços vazios prevalecem entre os níveis de microcristais de hematita granular.

Cristais subédricos de martita contendo relictos de kenomagnetita de cor rosa ocorrem de forma dispersa na rocha com granulação entre 0,10 e $0,20 \mathrm{~mm}$.

Assim como para o IFX, no ITX os minerais de hematita (Figura 6) de forma lamelar são mais frequentemente observados; os cristais de hematita nessas rochas apresentam forte orientação preferencial com a lineação mineral concordante à foliação.

Minerais acessórios descritos a seguir foram identificados a partir de análises utilizando o microscópio eletrônico de varredura - MEV (Figura 7). A amostra FD46_201,85 a 202,01 é um IFX coletado em furo de sonda dentro de um intervalo em que os teores de $\mathrm{Al}$ e $\mathrm{P}$ são relativamente elevados. Na análise petrográfica, essa amostra exibe a presença de cristais euédricos e subédricos de zircão ocorrendo na forma de minerais acessórios entre os níveis de minerais opacos da formação ferrífera.

A análise feita por meio das imagens de alta resolução confirmou a presença do zircão por meio do mapeamento químico qualitativo feito entre os minerais da rocha.
Tabela 3. Tipos de óxidos de ferro classificados segundo a definição de Hagemann et al. (2008).

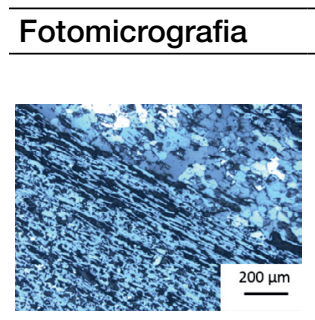

Descrição

Classificação

Cristais de

hematita

alongados

predominantes

entre os cristais de

óxidos de ferro que

estão presentes na

amostra de IFX.

Cristais de

hematita

alongados

com pequenos

comprimentos

presentes

principalmente nos

itabiritos.

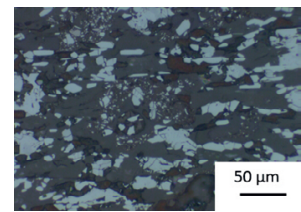

Cristais

compactos,

equidimensionais

de hematita com

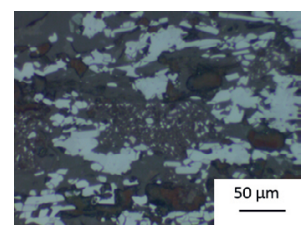

granulação fina.

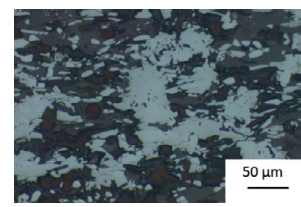

Cristais de

hematita

inequidimensionais

formando contatos

irregulares.

Aglomerados

anédricos,

porosos,

que ocorrem

associados

à hematita

microlamelar.

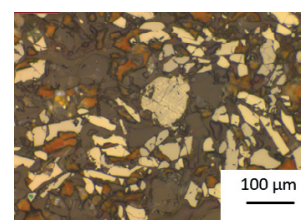

Pseudomorfos dos

cristais octaédricos de magnetita.

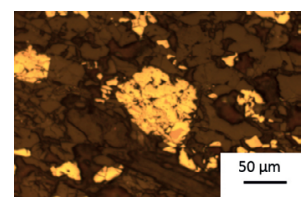

Fase intermediária

formada no

processo de

oxidação da

magnetita para

hematita (Kullerud

et al., 1969).

O mineral é

identificado em

cristais rosados no

interior dos cristais

de martita.

IFX: itabirito com alto teor de contaminantes.
Hematita

granular

Hematita

lobular

Hematita

anédrica

Hematita

lamelar

Hematita

microlamelar

anédica

\section{Martita}

Kenomagnetita 

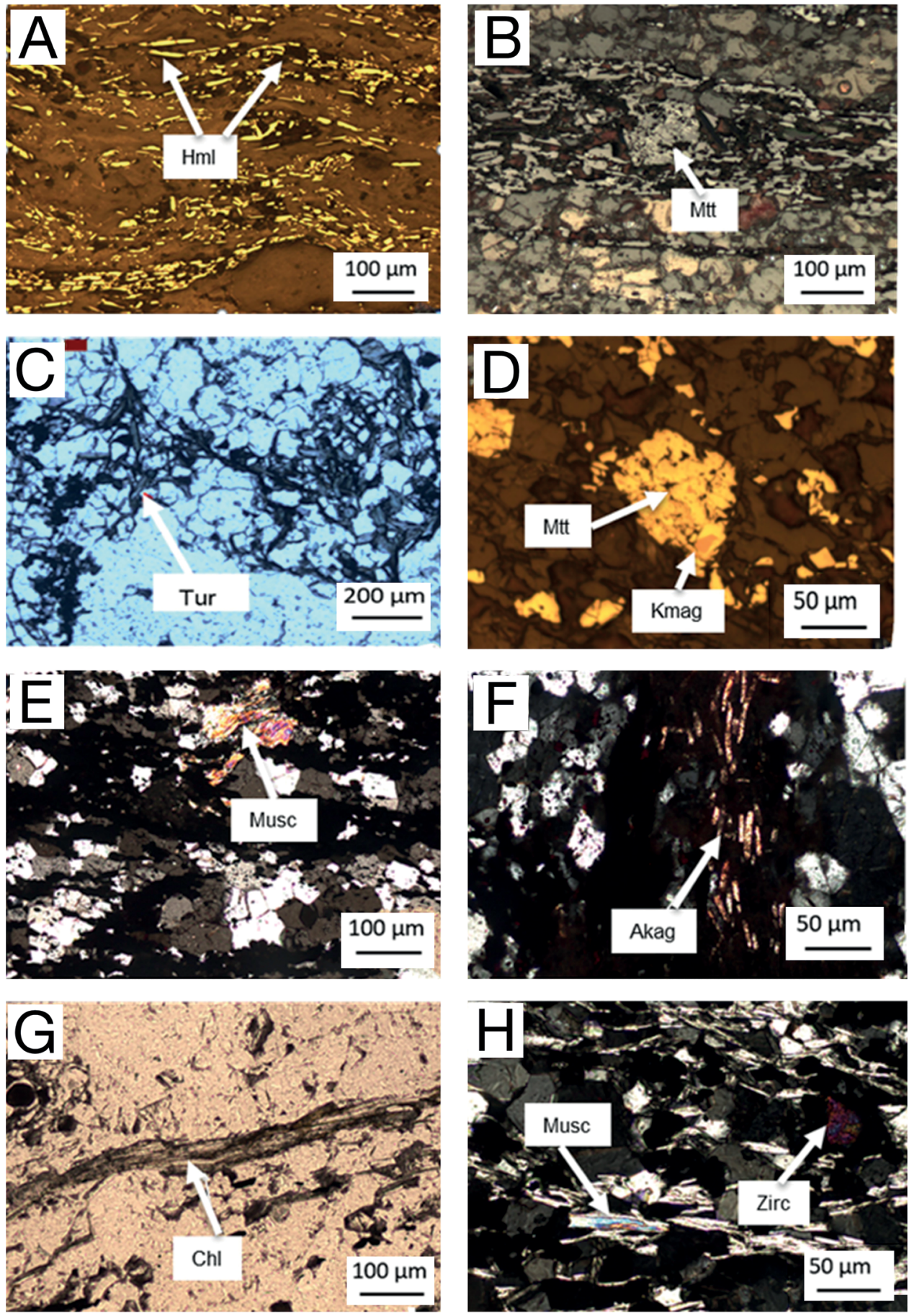

Hml: hematita microlamelar; Mtt: martita; Tur: turmalina; Kmag: kenomagnetita; Musc: muscovita; Akag: akaganeita; Chl: clorita; Zirc: zircão.

Figura 5. Fotomicrografias: (A) níveis contendo cristais aciculares de hematita microlamelar. Luz refletida; nicois paralelos; aumento de 100X; amostra FL001; (B) cristais de martita descritos na amostra FD37_128,25 a 128,35 m. Luz transmitida; aumento de 500X; (C) cristais de turmalina descritos na amostra FD37_128,25 a 128,35. Luz transmitida; aumento de 500X; (D) cristal de martita contendo relictos de kenomagnetita. Luz refletida; nicois cruzados; aumento de 500X; (E) muscovita descrita na amostra FD18_114,32 a 114,38 m; nicois cruzados; luz transmitida; aumento de 500X; (F) aspecto dos cristais de cor marrom, aciculares de akaganeita (Akag) orientados e descritos na amostra FD18_89,25 a 89,35. Luz transmitida; nicois cruzados, aumento de 100X; (G) clorita intercrescida entre os cristais de quartzo descrita na amostra FD37_128,25 a 128,35m. Luz transmitida, aumento de 500X; $(\mathrm{H})$ cristal de zircão inserido entre os níveis de minerais opacos da amostra FD46_201,85 a 202,01m. Luz transmitida, aumento de 100X. 

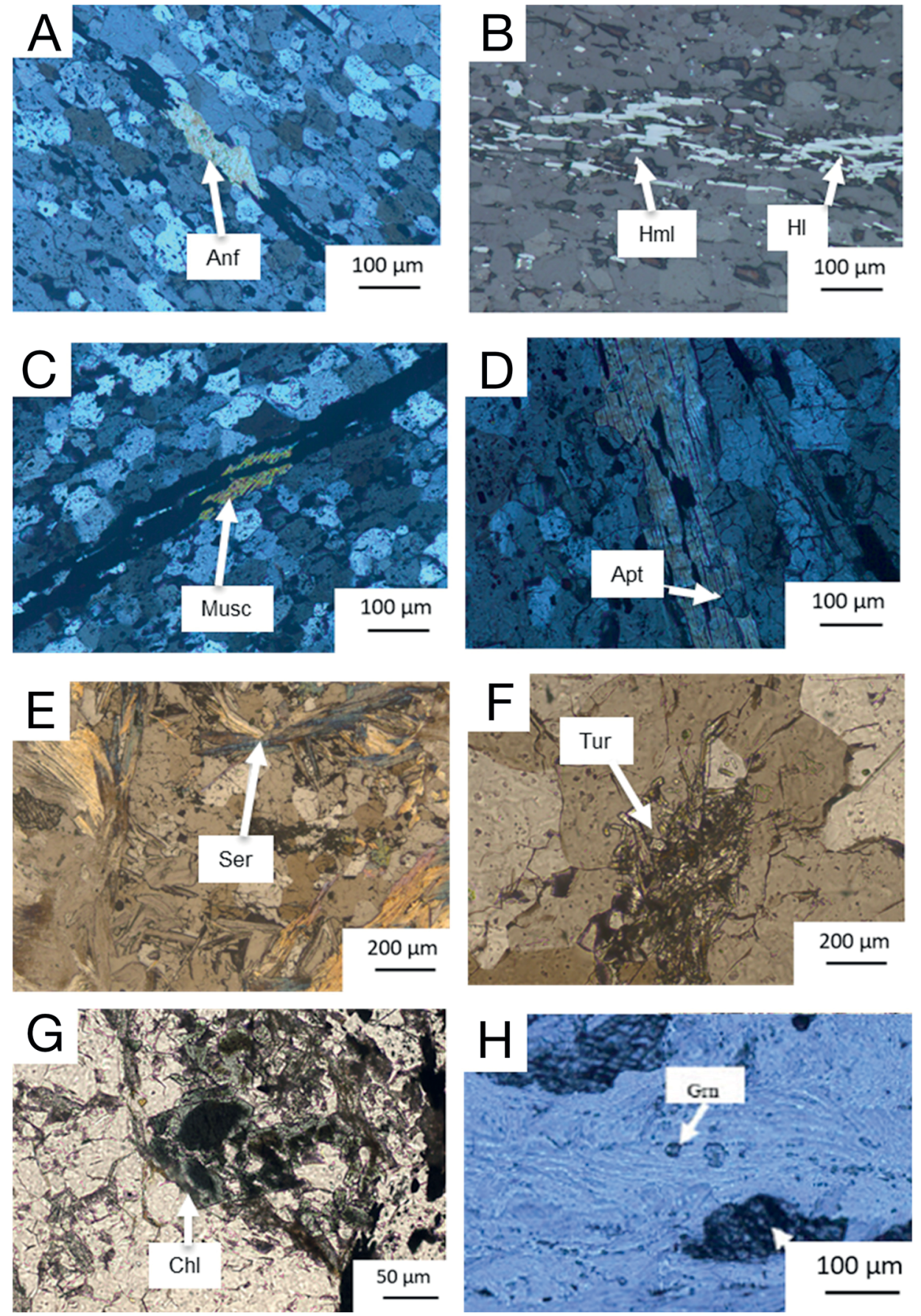

Anf: anfibólio; Hml: hematita microlamelar; Hl: hematita lamelar; Musc: muscovita; Apt: apatita; Ser: sericita; Tur: turmalina; Chl: clorita; Grn: granada.

Figura 6. Fotomicrografias: (A) cristal de anfibólio entre os níveis de hematita. Luz transmitida; nicois cruzados; aumento de 100X; amostra FD46_82,32 a 82,44; (B) níveis de hematita microlamelar alternado aos níveis ricos em quartzo. Luz refletida; nicois cruzados; aumento de 100X; FD46_82,32 a 82,44; (C) cristal de muscovita alongado, orientado segundo o bandamento e cortado pelo s níveis de hematita. Nicois cruzados. Luz refletida; aumento de 100X; amostra FD46_82,32 a 82,44; (D) cristal bem desenvolvido de apatita. Luz refletida; nicois cruzados; aumento de 100X; FD46_31,26 a 31,36; (E) cristais finos com orientação caótica de sericita entre os níveis ricos em quartzo. Aumento de 100X. Luz transmitida; nicois cruzados; FD46_31,26 a 31,36; (F) cristais finos de turmalina subcrescidos entre os cristais grossos de quartzo na amostra 31,26 a 31,36. Luz transmitida; aumento de 500X; (G) cristais de clorita entre os cristais de hematita. Nicois paralelos; luz transmitida; aumento de 500X; $(\mathrm{H})$ óxido de manganês e raro cristal de granada. Nicois praralelos; luz transmitida; aumento de 500X. Amostra FD46_31,26 a 31,36 m. 
Cristais de gibbsita que não haviam sido identificados na petrografia foram descritos com o auxílio das imagens de elétrons retroespalhados e da análise química qualitativa (EDS).

A análise química do zircão também revelou a presença de uma fase com cromo em um dos minerais analisados. Essa composição sugere a presença de um possível mineral de espinélio contendo $\mathrm{Fe}$ e $\mathrm{Cr}$ na composição.

$\mathrm{Na}$ amostra FD18_89,25 a 89,35m de IFX foram observados minerais de cor marrom, aciculares, orientados de acordo com o bandamento com granulação fina, podendo corresponder à akaganeíta $\left(\mathrm{Fe}^{3+}, \mathrm{Ni}^{2+}\right)_{8}(\mathrm{OH}, \mathrm{O})_{16} \mathrm{Cl}_{1,25}$ (Figura 5) .

$\mathrm{Na}$ amostra FD46 201,85 a 202,01m ocorrem cristais de zircão bem formados, granulação média a grossa com relevo alto incluso entre os níveis de minerais opacos da rocha.
Cristais de turmalina (Santos e Brandão, 2002; Cabral et al., 2013) cor verde ocorrem nas amostras FD37_128,25 a 128,35 e FD46_31,26 a 31,36 intercrescidos entre as fraturas do veio de quartzo que atravessa o itabirito. Esses minerais estão alinhados com granulação fina e fazem contato com minerais fibrosos de clorita cor verde.

\section{GEOQUÍMICA DE ROCHA TOTAL}

Os litotipos selecionados foram coletados primeiramente a partir das descrições macroscópicas dos testemunhos e das amostras das diferentes classificações dos itabiritos e, posteriormente, essas nomenclaturas foram confirmadas a
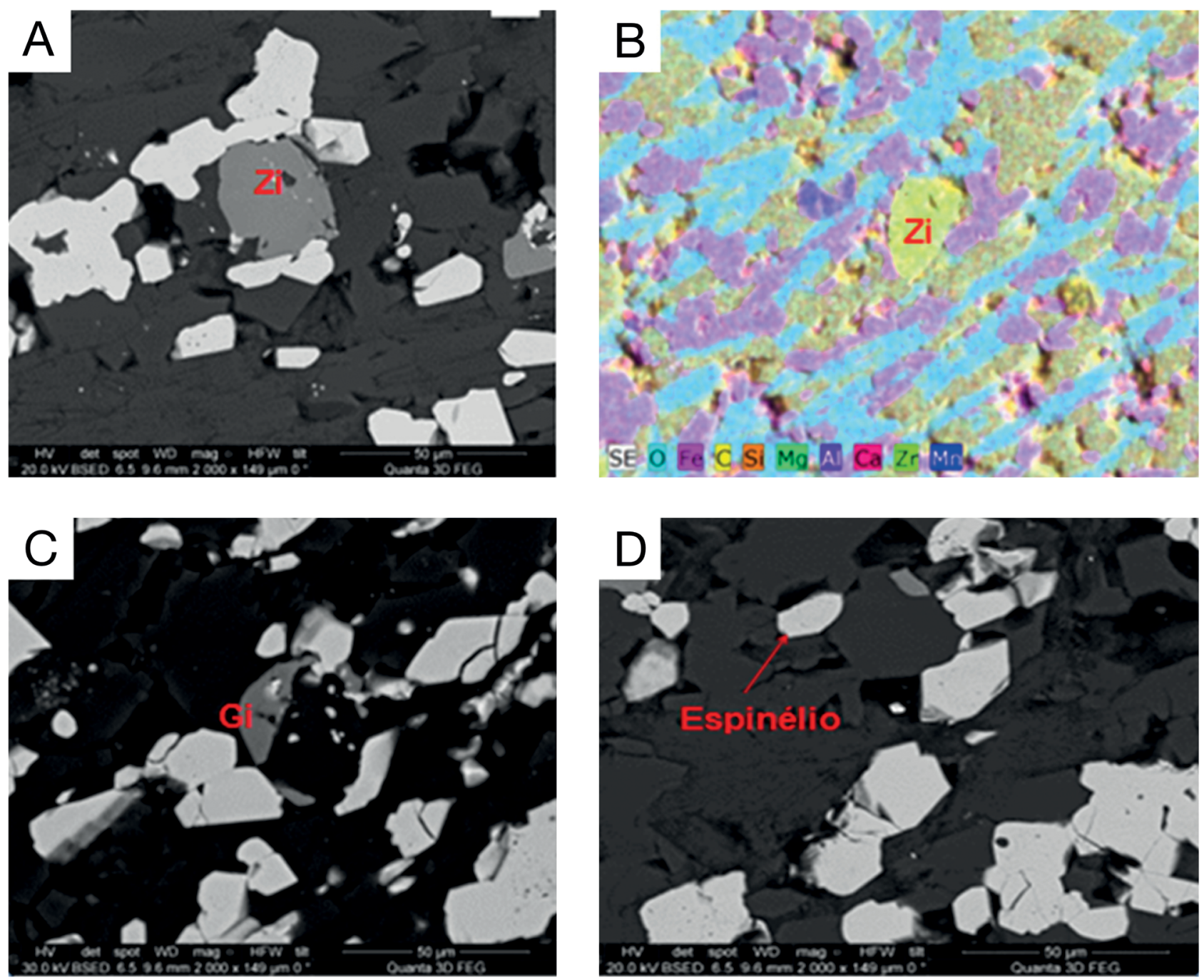

Zi: zircão; Gi: gibbsita

Figura 7. Imagem Backscattering - BSE. (A) Cristal de zircão entre os minerais de hematita; (B) mapeamento químico identificando a presença do zircão entre os minerais; (C) grão de gibbsita entre os minerais que compõem a amostra; (D) cristal identificado com cromo na composição sugerindo a presença de um possível mineral de espinélio. 
partir dos resultados químicos dos furos de sonda e amostra de campo em diferentes níveis topográficos do depósito mineral da Serra do Sapo.

A integração dos dados das análises químicas permite, em conjunto com uma investigação mineralógica, uma discussão acerca das fontes de formação dos minerais que compõem as rochas da jazida.
A Tabela 4 mostra os dados químicos composicionais de dez amostras selecionadas entre os diferentes tipos de itabirito.

Para as amostras selecionadas foram realizadas determinações de elementos maiores e traços procurando abranger os diferentes tipos de IT, IFX e ITX, classificados por meio de seu nível de intemperismo. As classificações para

Tabela 4. Resultado da análise química das amostras de itabirito (ver Tabela 2).

\begin{tabular}{|c|c|c|c|c|c|c|c|c|c|c|}
\hline $\begin{array}{l}\text { Classificação } \\
\text { do itabirito }\end{array}$ & IFX & IFX & IFX & IT & ITX & ITX & ITX & ITX & IFX & IFX \\
\hline Amostra & FD451_01 & FD451_03 & FD451_04 & FD18_05 & FD37_05 & FD37_07 & FD37_08 & FD46_05 & FD46_09 & FL_001 \\
\hline \multicolumn{11}{|c|}{ 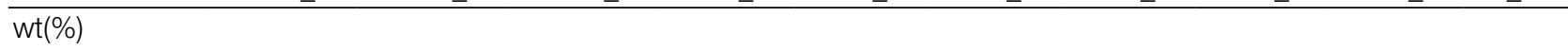 } \\
\hline $\mathrm{SiO}_{2}$ & 17,85 & 1,48 & 59,93 & 46,86 & 53,52 & 55,62 & 44,81 & 77,46 & 36,41 & 10,04 \\
\hline $\mathrm{Al}_{2} \mathrm{O}_{3}$ & 15,18 & 1,13 & 1,23 & 1,7 & 0,39 & 1,17 & 0,18 & 0,16 & 5,17 & 9,98 \\
\hline $\mathrm{Fe}_{2} \mathrm{O}_{3}$ & 53,77 & 93,51 & 33,76 & 48,42 & 42,06 & 40,31 & 54,16 & 19,91 & 47,91 & 69,03 \\
\hline $\mathrm{CaO}$ & $<0,01$ & $<0,01$ & $<0,01$ & 0,07 & 0,99 & 0,23 & $<0,01$ & 1,01 & 0,18 & 0,01 \\
\hline $\mathrm{MgO}$ & 0,04 & 0,03 & 0,05 & 0,37 & 0,45 & 1,05 & 0,02 & 0,08 & 5,12 & 0,09 \\
\hline $\mathrm{Na}_{2} \mathrm{O}$ & $<0,01$ & $<0,01$ & $<0,01$ & $<0,01$ & $<0,01$ & $<0,01$ & $<0,01$ & $<0,01$ & $<0,01$ & $<0,01$ \\
\hline $\mathrm{K}_{2} \mathrm{O}$ & $<0,01$ & 0,02 & 0,23 & $<0,01$ & $<0,01$ & $<0,01$ & $<0,01$ & $<0,01$ & 0,5 & 0,22 \\
\hline $\mathrm{MnO}$ & 0,01 & 0,03 & 0,01 & 0,3 & 0,17 & 0,07 & 0,01 & 0,08 & 1,07 & 1,36 \\
\hline $\mathrm{TiO}_{2}$ & 0,86 & 0,41 & 0,03 & 0,04 & 0,02 & 0,06 & $<0,01$ & 0,01 & 0,27 & 0,47 \\
\hline $\mathrm{P}_{2} \mathrm{O}_{5}$ & 0,05 & 0,04 & 0,05 & 0,08 & 0,61 & 0,17 & 0,01 & 0,75 & 0,11 & 0,21 \\
\hline $\mathrm{Cr}_{2} \mathrm{O}_{3}$ & 0,03 & $<0,01$ & $<0,01$ & $<0,01$ & $<0,01$ & $<0,01$ & $<0,01$ & $<0,01$ & $<0,01$ & 0,03 \\
\hline LOI & 11,82 & 2,88 & 3,99 & 1,17 & 0,88 & 0,64 & 0,06 & 0,18 & 2,65 & 7,91 \\
\hline $\mathrm{FeO}$ & 1,1 & 1,03 & 1,23 & 0,4 & 0,64 & 1,21 & 0,48 & 0,53 & 0,36 & 0,78 \\
\hline \multicolumn{11}{|l|}{ Ppm } \\
\hline $\mathrm{Ba}$ & 22 & 43 & 374 & 59 & 22 & 10 & 16 & 14 & 510 & 536 \\
\hline $\mathrm{Be}$ & 2 & $<1$ & $<1$ & 3 & 1 & 2 & $<1$ & $<1$ & 2 & 3 \\
\hline Co & 2,9 & 0,7 & 0,9 & 7,5 & 1,8 & 3,8 & 1 & 0,9 & 26,5 & 2,2 \\
\hline Cs & $<0,1$ & 0,1 & 0,2 & $<0,1$ & 0,1 & $<0,1$ & $<0,1$ & $<0,1$ & 0,6 & $<0,1$ \\
\hline $\mathrm{Ga}$ & 14,9 & 5 & 1,9 & 4,5 & 0,8 & 1,9 & 0,6 & 0,7 & 9 & 11,1 \\
\hline $\mathrm{Hf}$ & 5,1 & 0,4 & 0,3 & 0,3 & 0,2 & 0,6 & $<0,1$ & $<0,1$ & 6,3 & 3,2 \\
\hline $\mathrm{Nb}$ & 11 & 4 & 0,6 & 0,7 & 0,2 & 0,7 & 0,2 & 0,4 & 5,9 & 4,5 \\
\hline $\mathrm{Rb}$ & 0,2 & 0,9 & 7,5 & $<0,1$ & 0,3 & $<0,1$ & $<0,1$ & 0,2 & 16 & 6,2 \\
\hline Sn & 3 & 2 & $<1$ & $<1$ & $<1$ & $<1$ & $<1$ & $<1$ & 1 & 2 \\
\hline $\mathrm{Sr}$ & 14,2 & 18,6 & 30,3 & 4,8 & 8,6 & 2,5 & 1 & 7,4 & 4,2 & 40,9 \\
\hline $\mathrm{Ta}$ & 0,8 & 0,2 & $<0,1$ & $<0,1$ & $<0,1$ & $<0,1$ & $<0,1$ & $<0,1$ & 0,5 & 0,4 \\
\hline Th & 13,7 & 1,8 & 1,6 & 0,5 & $<0,2$ & 1,1 & $<0,2$ & 0,2 & 12,5 & 9,7 \\
\hline U & 4,3 & 4,7 & 0,8 & 1,9 & 1,5 & 1,8 & 1 & 2,4 & 8,1 & 5,6 \\
\hline V & 396 & 133 & 29 & 97 & 37 & 21 & 12 & 23 & 93 & 128 \\
\hline $\mathrm{Zn}$ & 13 & 8 & 4 & 19 & 34 & 34 & 4 & 7 & 39 & 43 \\
\hline W & 2 & 0,8 & 1,5 & 12,2 & 2,6 & 2 & 1,4 & 4 & 2,5 & 2,5 \\
\hline $\mathrm{Zr}$ & 180,9 & 21,1 & 11,5 & 11,8 & 5,2 & 23,8 & 3,7 & 4,8 & 277,5 & 134,2 \\
\hline Mo & 0,2 & 0,5 & 0,8 & 0,5 & 0,4 & 0,5 & 0,6 & 0,6 & 0,4 & 1,6 \\
\hline $\mathrm{Cu}$ & 4,7 & 3,6 & 3,6 & 1,5 & 2,2 & 8,8 & 2 & 1,7 & 3,7 & 2,8 \\
\hline $\mathrm{Pb}$ & 22,1 & 7,4 & 1,2 & 4,2 & 2,3 & 2,5 & 1,6 & 3,2 & 12,4 & 43,8 \\
\hline $\mathrm{Ni}$ & 4,2 & 5,1 & 2,2 & 18,5 & 3 & 6,3 & 2,6 & 5,4 & 43 & 11,6 \\
\hline As & 7,5 & 6,2 & 2 & 20,1 & 4,6 & 2,8 & 1,5 & 62,8 & 17,5 & 23 \\
\hline $\mathrm{Sb}$ & 0,1 & 0,5 & 0,4 & 0,8 & 0,5 & 0,3 & 0,6 & 0,5 & 0,1 & 0,2 \\
\hline $\mathrm{Bi}$ & $<0,1$ & 0,4 & $<0,1$ & $<0,1$ & $<0,1$ & $<0,1$ & $<0,1$ & $<0,1$ & 0,2 & 0,4 \\
\hline
\end{tabular}


Tabela 4. Continuação.

\begin{tabular}{|c|c|c|c|c|c|c|c|c|c|c|}
\hline Amostra & FD451_01 & FD451_03 & FD451_04 & FD18_05 & FD37_05 & FD37_07 & FD37_08 & FD46_05 & FD46_09 & FL_001 \\
\hline $\mathrm{Hg}$ & $<0,01$ & $<0,01$ & $<0,01$ & $<0,01$ & $<0,01$ & $<0,01$ & $<0,01$ & $<0,01$ & $<0,01$ & 0,03 \\
\hline $\mathrm{Ti}$ & 0,86 & 0,41 & 0,03 & 0,04 & 0,02 & 0,06 & $<0,01$ & 0,01 & 0,27 & 0,47 \\
\hline Y & 7,8 & 9,4 & 17,3 & 17,8 & 14 & 4,8 & 3,8 & 12,1 & 31 & 14,4 \\
\hline $\mathrm{La}$ & 30,7 & 16,3 & 22,7 & 7,4 & 3 & 1,7 & 1,5 & 2,4 & 19,2 & 47,3 \\
\hline $\mathrm{Ce}$ & 53,3 & 33,2 & 68,1 & 14 & 5 & 2,7 & 2 & 3,3 & 45,4 & 80,1 \\
\hline $\operatorname{Pr}$ & 5,38 & 3,34 & 5,9 & 1,36 & 0,72 & 0,29 & 0,27 & 0,48 & 4 & 9,1 \\
\hline $\mathrm{Nd}$ & 17,2 & 10,1 & 21,9 & 6,1 & 3 & 1,3 & 0,7 & 2,6 & 15,6 & 31,5 \\
\hline $\mathrm{Sm}$ & 2,79 & 1,75 & 4,87 & 0,96 & 0,82 & 0,51 & 0,27 & 0,6 & 3,49 & 5,48 \\
\hline Eu & 0,69 & 0,35 & 1,36 & 0,45 & 0,36 & 0,09 & 0,07 & 0,21 & 0,71 & 1,52 \\
\hline $\mathrm{Gd}$ & 2,08 & 1,44 & 4,37 & 1,25 & 1,23 & 0,42 & 0,28 & 0,85 & 3,66 & 4,16 \\
\hline $\mathrm{Tb}$ & 0,3 & 0,2 & 0,58 & 0,2 & 0,21 & 0,07 & 0,05 & 0,13 & 0,68 & 0,57 \\
\hline Dy & 1,69 & 1,48 & 3,07 & 1,59 & 1,43 & 0,48 & 0,43 & 1,09 & 4,3 & 3,25 \\
\hline Ho & 0,38 & 0,33 & 0,61 & 0,39 & 0,34 & 0,12 & 0,1 & 0,25 & 1,01 & 0,65 \\
\hline Er & 1,29 & 1,1 & 1,81 & 1,24 & 1,05 & 0,46 & 0,38 & 1 & 3,17 & 1,7 \\
\hline $\mathrm{Tm}$ & 0,19 & 0,13 & 0,23 & 0,21 & 0,17 & 0,06 & 0,06 & 0,14 & 0,49 & 0,26 \\
\hline $\mathrm{Yb}$ & 1,33 & 0,71 & 1,4 & 1,32 & 1,02 & 0,42 & 0,33 & 0,9 & 3,21 & 1,79 \\
\hline $\mathrm{Lu}$ & 0,21 & 0,12 & 0,2 & 0,23 & 0,17 & 0,08 & 0,07 & 0,18 & 0,51 & 0,32 \\
\hline \multicolumn{11}{|l|}{ Ppb } \\
\hline $\mathrm{Au}$ & 1,3 & $<0,5$ & $<0,5$ & 0,7 & $<0,5$ & $<0,5$ & 1,5 & 1 & 2,4 & 1,1 \\
\hline $\begin{array}{l}\text { ETR } \\
\text { normalizados } \\
\text { PAAS } \\
\text { (McLennan, } \\
\text { 1989) }\end{array}$ & FD451_01 & FD451_03 & FD451_04 & FD18_05 & FD37_05 & FD37_07 & FD37_08 & FD46_05 & FD46_09 & FL_001 \\
\hline$\sum$ ETR & 117,53 & 70,55 & 137,1 & 36,7 & 18,52 & 8,7 & 6,51 & 14,13 & 105,43 & 187,7 \\
\hline $\operatorname{Pr} / \mathrm{Yb}_{(\mathrm{SN})}$ & 1,292 & 1,502 & 1,346 & 0,329 & 0,255 & 0,221 & 0,261 & 0,17 & 0,398 & 1,624 \\
\hline $\mathrm{Sm} / \mathrm{Yb}_{(\mathrm{SN})}$ & 1,066 & 1,252 & 1,767 & 0,37 & 0,408 & 0,617 & 0,416 & 0,339 & 0,552 & 1,556 \\
\hline $\mathrm{Ce} / \mathrm{Ce}^{\star}{ }_{(\mathrm{SN})}$ & 0,948 & 1,036 & 1,355 & 1,012 & 0,785 & 0,877 & 0,719 & 0,708 & 1,194 & 0,887 \\
\hline $\operatorname{Pr} / \mathrm{Pr}^{*}{ }_{(\mathrm{SN})}$ & 1,035 & 1,058 & 0,89 & 0,866 & 1,078 & 0,909 & 1,336 & 0,92 & 0,879 & 1,065 \\
\hline $\mathrm{Eu} / \mathrm{Eu}^{*}{ }_{(\mathrm{SN})}$ & 1,39 & 1,105 & 1,524 & 2,089 & 1,782 & 0,921 & 1,213 & 1,534 & 0,933 & 1,573 \\
\hline $\mathrm{Y} / \mathrm{Ho}$ & 20,526 & 28,485 & 28,361 & 45,641 & 41,176 & 40 & 38 & 48,4 & 30,693 & 22,154 \\
\hline$Y / Y_{(S N)}$ & 0,776 & 1,072 & 1,008 & 1,798 & 1,599 & 1,59 & 1,46 & 1,847 & 1,185 & 0,79 \\
\hline
\end{tabular}

IFX: itabirito com alto teor de contaminantes; IT: itabirito; ITX: itabirito com alto teor de fósforo; ETR: elementos terras raras; PAAS: Pos-Archean Australian Shale.

essas amostras foram feitas a partir dos intervalos descritos macroscopicamente nos testemunhos de sondagem. Esses dois litotipos de itabiritos têm teores relativamente altos de $\mathrm{P}$ e $\mathrm{Al}$ na sua composição.

A Figura 8 ilustra o comportamento dos elementos maiores para os diferentes tipos de itabirito.

As amostras demonstram teores de $\mathrm{Fe}_{2} \mathrm{O}_{3}$ entre 33,76 e $93,51 \%$ (em peso) para o IFX (Figura 7B) e de 19,91 a $54,16 \%$ para o ITX (Tabela 2 e Figura $6 \mathrm{C}$ ). Os teores de $\mathrm{Al}_{2} \mathrm{O}_{3}$ no IFX variam de 1,13 a $15,18 \%$, em geral bem maiores do que os mesmos teores para as amostras de ITX, que variam de 0,18 a $1,17 \%$, e para a amostra de IT, com $1,7 \%$.

Os teores de $\mathrm{SiO}_{2}$ variam de 44,81 a $77,46 \%$ para a composição do ITX, que são, em média, maiores do que os
$46,86 \%$ encontrados para a amostra de IT. Para o IFX, esses resultados são ainda menores se comparados às médias de $\mathrm{SiO}_{2}$ para as duas litologias.

Para os teores de $\mathrm{P}_{2} \mathrm{O}_{5}$, destacam-se os valores de $0,61 \mathrm{e}$ $0,75 \%$ para as amostras de ITX. Essas concentrações, apesar de serem baixas, são relativamente elevadas se comparadas às concentrações obtidas para as amostras de IT e IFX.

Os valores de $\mathrm{MgO}$ foram detectados para todas as amostras com alta concentração de 5,12\% para a amostra de IFX FD46_09 (Tabela 4 e Figura 8). Concentrações de $\mathrm{MnO}$ também foram detectadas para todas as amostras com alta concentração de 1,37\% para a amostra de IFX FL_001.

Apesar das baixas concentrações de $\mathrm{TiO}_{2}$, apenas a amostra de ITX FD37_08 obteve resultado abaixo do limite de detecção. 
Concentrações de $\mathrm{Ba}, \mathrm{Cr}_{2} \mathrm{O}_{3}$ e $\mathrm{K}_{2} \mathrm{O}$ foram detectadas em maior quantidade nas amostras de IFX (Tabela 4), sendo 374 ppm (FD451_04), 510 ppm (FD46_09) e 536 ppm (FL_001) para o Ba; 0,03\% (FD451_01 e FL_001) para os resultados de $\mathrm{Cr}_{2} \mathrm{O}_{3}$; e $0,02 \%$ (FD451_03), $0,23 \%$ (FD451_04), 0,5\% (FD46_09) e 0,22\% (FL_001) para o K O.

Os padrões dos elementos-traço mostram $\mathrm{Ba}, \mathrm{V}$ e $\mathrm{Zr}$ com as maiores concentrações (Figura 9A). A amostra ITX FD46_05 tem alta concentração de As, com 62,8 ppm, assim como as amostras de ITX FD37_07 e FD37_05 com alta concentração de Zn, com 34 ppm. Esses valores de zinco são similares às concentrações do mesmo elemento para as amostras de IFX FD46_09, com 39 ppm, e FL_001, com $43 \mathrm{ppm}$ (Figura 9B).

Concentrações de $\mathrm{Ag}$ foram as únicas abaixo do limite de deteç̧ão para todas as amostras. Concentrações de $\mathrm{Hg}$ apenas ficaram acima do limite de detecção para a amostra FL_001, com 0,03 ppm.

As amostras de IFX mostram concentrações bem mais elevadas de $\mathrm{Nb}(11,4,0,6,5,9$ e 4,5 ppm) se comparadas à amostra de IT $(0,7 \mathrm{ppm})$ e às amostras de $\operatorname{ITX}(0,2,0,7$, $0,2$ e $0,4 \mathrm{ppm})$.

Assim como o Ba que obteve altas concentrações de 374 ppm (FD451_04), 510 ppm (FD46_09) e 536 ppm (FL_001) para as amostras de IFX, o Zr também mostra valores de 180,9 ppm (FD451 001), 277,5 ppm (FD46 09) e 134,2 ppm (FL_001) para essa mesma classificação de itabirito.

Os elementos terras raras (ETR) foram normalizados aos padrões Post-Archean Australian Shale - PAAS ${ }_{(\mathrm{SN})}$ (McLennan, 1989) e aos condritos (NC) (Taylor e McLennan, 1985). O Y foi adicionado entre o Dy e o Ho, assim como mostram os números usados na base de cálculo informados na Tabela 4. A soma dos ETR ( $\sum$ ETR) para as amostras de IFX varia de 70,55 a 187,7 ppm e de 6,51 a 18,52 ppm para as amostras de ITX. A amostra de itabirito FD18_05 mostra uma soma de 36,7 ppm. Quando normalizado ao PAAS, o padrão de ETR do IFX é, em geral, caracterizado por leve enriquecimento dos elementos terras raras leves (ETRL) em relação aos elementos terras raras pesados (ETRP), com razão $\mathrm{Pr} / \mathrm{Yb}_{(\mathrm{snn})}$ variando entre 1,292 e 1,624. Somente a amostra de IFX FD46_09 mostrou enriquecimento dos ETRP em relação aos ETRL, com razão $\mathrm{Pr} / \mathrm{Yb}_{(\mathrm{sn})}=0,398$. As amostras de itabirito (Figura 10A) apresentaram razões $\mathrm{Pr} / \mathrm{Yb}_{\text {(sn) }}$ variando entre 0,170 e 0,261 , semelhante à amostra FD18_05, com razão 0,329 e leve enriquecimento dos ETRP em relação ao ETRL.

Razões $\mathrm{Sm} / \mathrm{Yb}_{(\mathrm{SN})}$ mostram enriquecimento dos ETRL em relação aos ETRP, com razões variando de 1,066 a 1,767 para as amostras de IFX (Figura 10B), com exceção da amostra de IFX FD46_09 com $\mathrm{Sm} / \mathrm{Yb}_{(\mathrm{SN})}=0,552$,

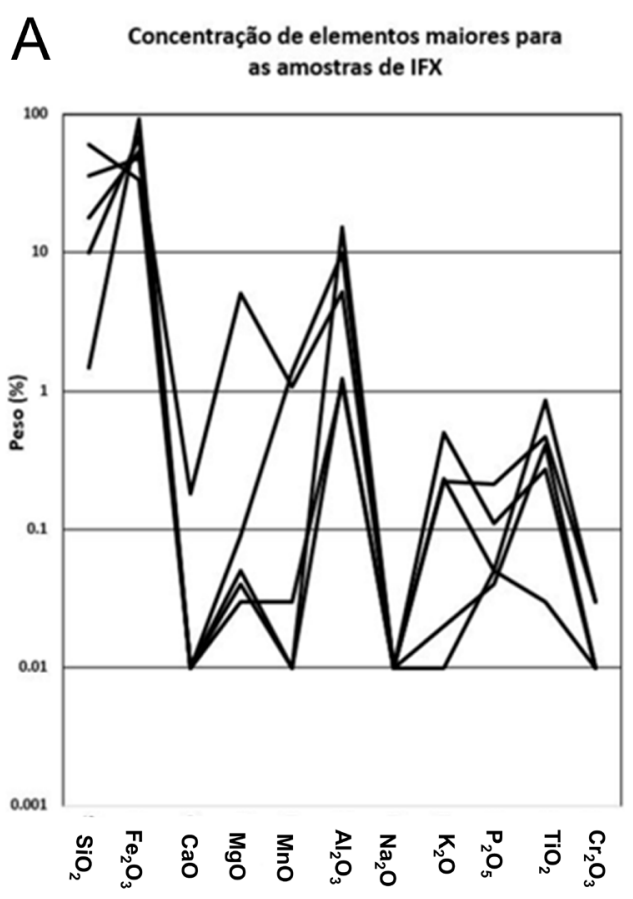

Elementos maiores
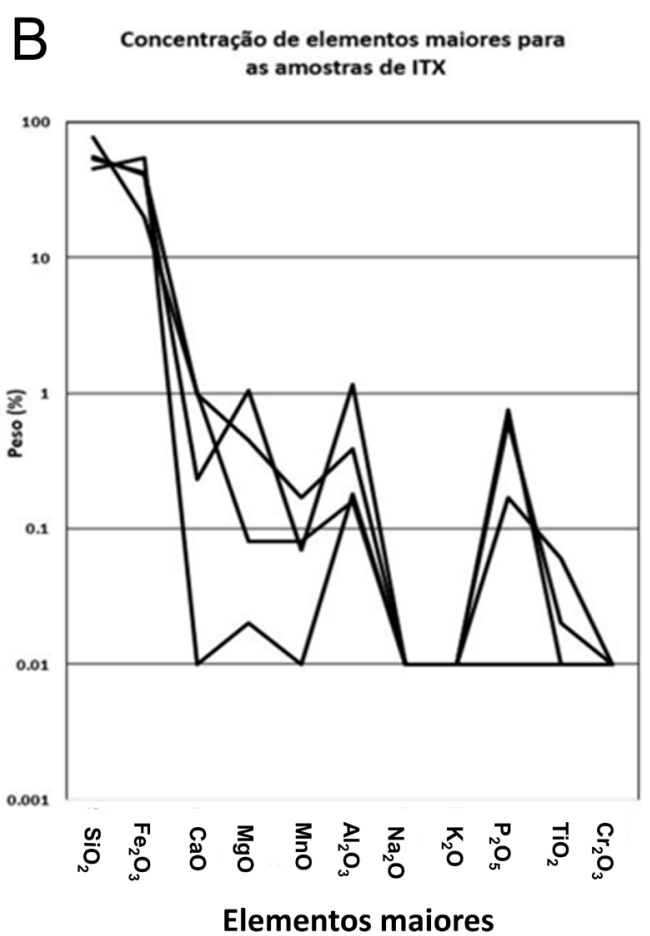

IFX: itabirito com alto teor de contaminantes; ITX: itabirito com alto teor de fósforo.

Figura 8. Concentração de elementos maiores. (A) Diagrama de concentração de elementos maiores para as amostras de itabirito com alto teor de contaminantes; (B) diagrama de concentração de elementos maiores para as amostras de itabirito com alto teor de fósforo. 

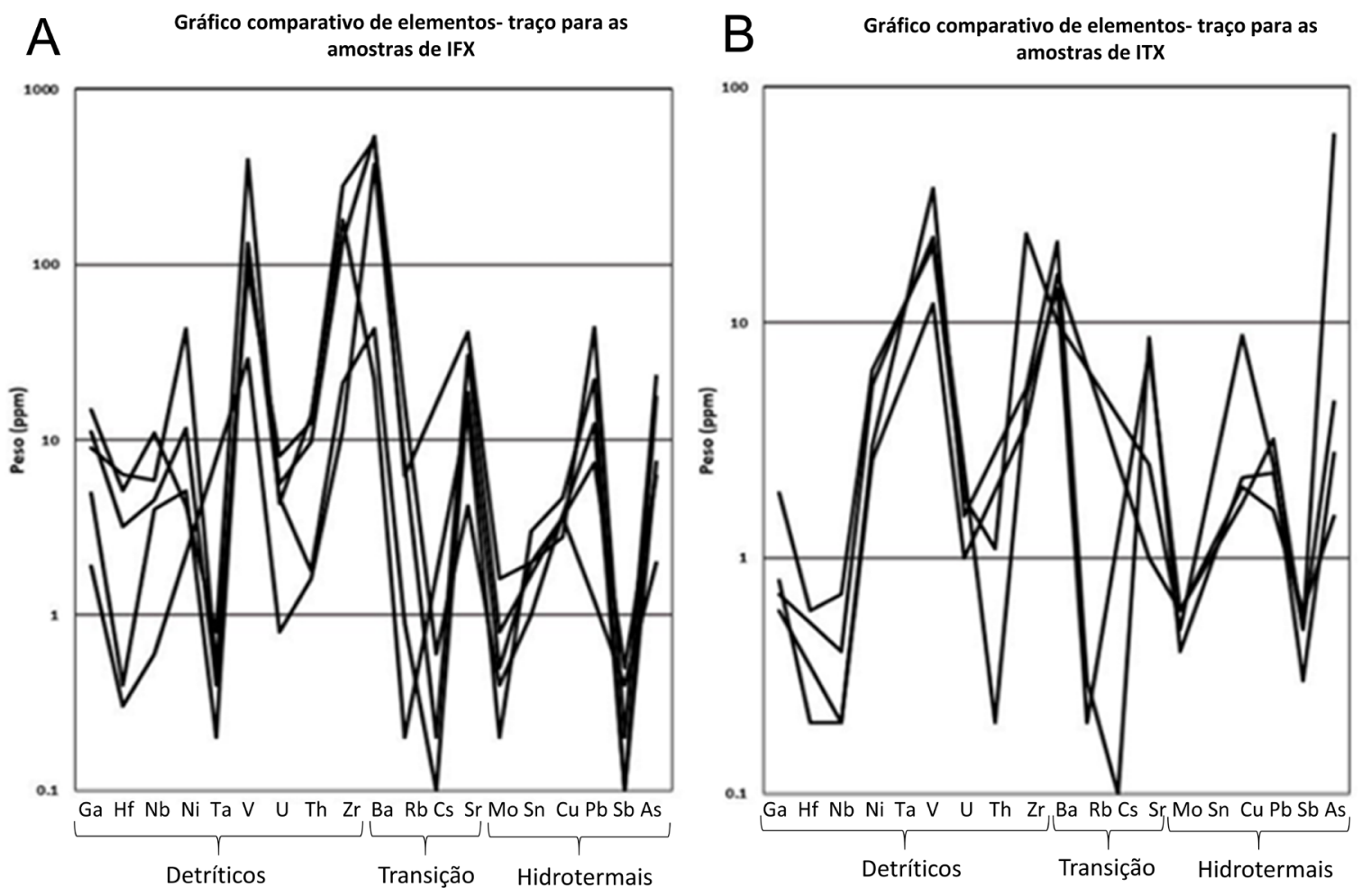

IFX: itabirito com alto teor de contaminantes; ITX: itabirito com alto teor de fósforo.

Figura 9. Elementos-traço discriminando os elementos de origem detrítica, de transição e hidrotermais; (A) diagrama de concentração de elementos-traço para as amostras de itabirito com alto teor de contaminantes; (B) diagrama de concentração de elementos-traço para as amostras de itabirito com alto teor de fósforo.
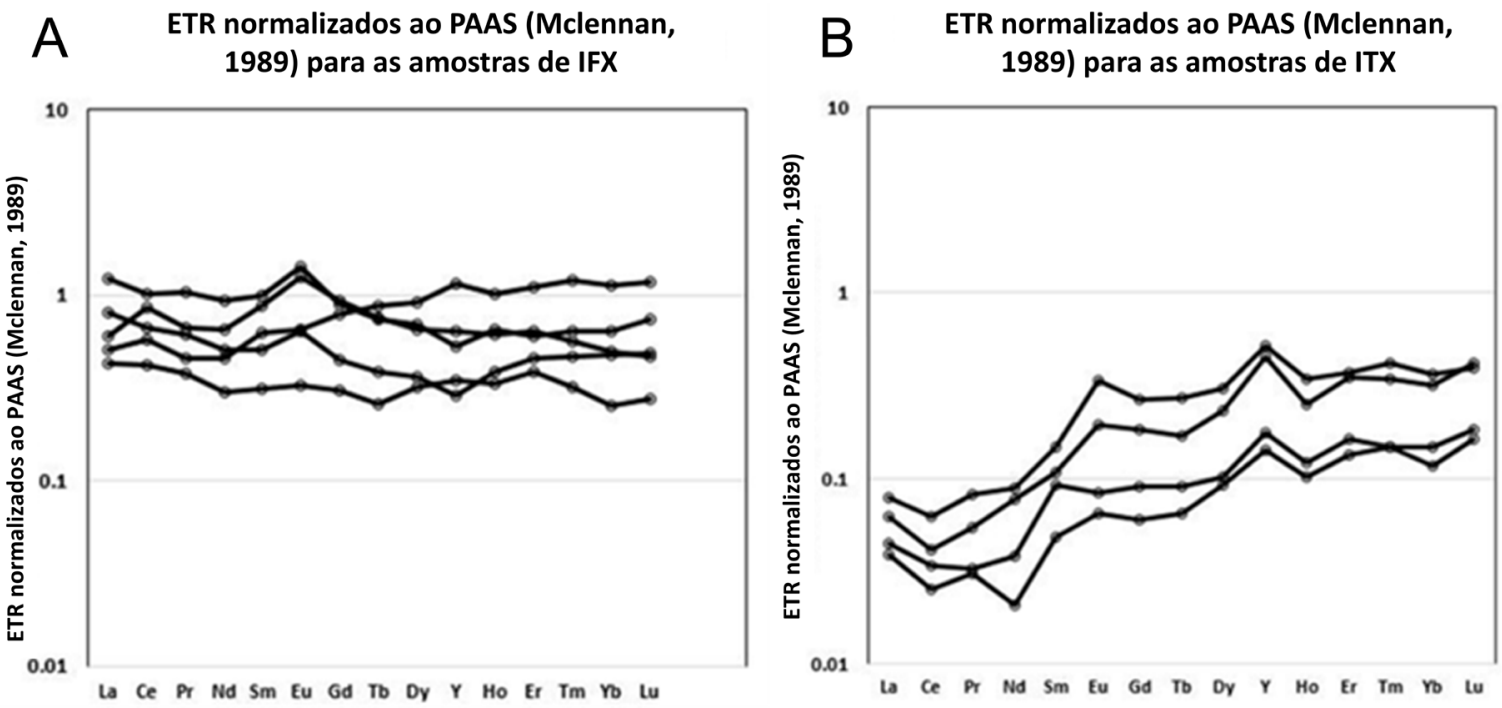

ETR: elementos terras raras; PAAS: Post-Archean Australian Shale; IFX: itabirito com alto teor de contaminantes; ITX: itabirito com alto teor de fósforo.

Figura 10. Elementos terras raras normalizados ao padrão Post-Archean Australian Shale. (A) Diagrama de elementos terras raras normalizado ao Post-Archean Australian Shale para as amostras de itabirito com alto teor de contaminantes; (B) diagrama de elementos terras raras normalizado ao Post-Archean Australian Shale para as amostras de itabirito com alto teor de fósforo. 
semelhante às razões de ITX com $\mathrm{Sm} / \mathrm{Yb}_{(\mathrm{SN})}=0,339-0,617$ e IT com $\mathrm{Sm} / \mathrm{Yb}_{(\mathrm{SN})}=0,370$. Para as amostras de IFX, os diagramas apresentam anomalia de Eu variando de $(\mathrm{Eu} /$ $\left.\mathrm{Eu}_{*_{(\mathrm{SN})}}\right)=\left(\mathrm{Eu}_{(\mathrm{SN})} /\left(0,66 \mathrm{Sm}_{(\mathrm{SN})}+0,33 \mathrm{~Tb}_{(\mathrm{SN})}\right)=0,932-1,573\right.$, enquanto para as amostras de ITX, esses resultados variam $\operatorname{de}\left(\mathrm{Eu} / \mathrm{Eu}_{*_{(\mathrm{SN})}}\right)=\left(\mathrm{Eu}_{(\mathrm{SN})} /\left(0,66 \mathrm{Sm}_{(\mathrm{SN})}+0,33 \mathrm{~Tb}_{(\mathrm{SN})}\right)=0,921-\right.$ 1,782. A razão de Eu para a amostra de IT foi $\left(\mathrm{Eu} / \mathrm{Eu}^{*}{ }_{(\mathrm{SN})}\right)=$ $\left(\mathrm{Eu}_{(\mathrm{SN})} /\left(0,66 \mathrm{Sm}_{(\mathrm{SN})}+0,33 \mathrm{~Tb}_{(\mathrm{SN})}\right)=2,089\right.$, calculada de acordo com Planavsky et al. (2010).

As amostras de IFX FD451_01 e FL001 são as únicas que apresentaram anomalia negativa de $\mathrm{Y} / \mathrm{Y}^{*}$, com razões de 0,776 e 0,790 , diferente das amostras de ITX, com razões $\left(\mathrm{Y} / \mathrm{Y}^{*}{ }_{(\mathrm{SN})}\right)$ $=\left(\mathrm{Y}_{(\mathrm{SN})} /\left(0,5 \mathrm{Dy} \mathrm{y}_{(\mathrm{SN})}+0,5 \mathrm{Ho}_{(\mathrm{SN})}\right)=1,460-1,847\right.$, e da amostra de IT, com razão $\left(\mathrm{Y}^{\prime} \mathrm{Y}_{(\mathrm{SN})}^{*}\right)=\left(\mathrm{Y}_{(\mathrm{SN})} /\left(0,5 \mathrm{Dy}_{(\mathrm{SN})}+0,5 \mathrm{Ho}_{(\mathrm{SN})}\right)=1,798\right.$.

Quando normalizados ao condrito (Taylor e McLennan, 1985), as amostras de IFX (Figura 11A) mostram maior enriquecimento de ETRL em relação ao ETRP do que as amostras de ITX (Figura 11B). O padrão das amostras de IFX é semelhante ao da amostra de IT (FD18_05).

A anomalia de Eu para todas as amostras indica leve padrão negativo, com $\left(\mathrm{Eu} / \mathrm{Eu}^{*}{ }_{(\mathrm{CN})}\right)=\left(\mathrm{Eu}_{(\mathrm{CN})} / \mathrm{Sm}_{(\mathrm{CN})}+\mathrm{Gd}_{(\mathrm{CN})}\right)$ $=0,301-0,468$ para as amostras de IFX e $\left(\mathrm{Eu} / \mathrm{Eu}^{*}{ }_{(\mathrm{CN})}\right)=$ $\left(\mathrm{Eu}_{(\mathrm{CN})} / \mathrm{Sm}_{(\mathrm{CN})}+\mathrm{Gd}_{(\mathrm{CN})}\right)=0,289-0,547$ para o ITX.

Semelhantemente à anomalia de $\mathrm{Eu}, \mathrm{a}$ anomalia de $\mathrm{Ce}$ também mostrou padrão negativo para as amostras com $\left(\mathrm{Ce} / \mathrm{Ce}_{*_{(\mathrm{CN})}}\right)=\left(\mathrm{Ce}_{(\mathrm{CN})} / \mathrm{La}_{(\mathrm{CN})}+\mathrm{Pr}_{(\mathrm{CN})}\right)=0,486$ para o IT; $\left(\mathrm{Ce} / \mathrm{Ce}^{*}{ }_{(\mathrm{CN})}\right)=\left(\mathrm{Ce}_{(\mathrm{CN})} / \mathrm{La}_{(\mathrm{CN})}+\operatorname{Pr}_{(\mathrm{CN})}\right)=0,429-0,678$ para
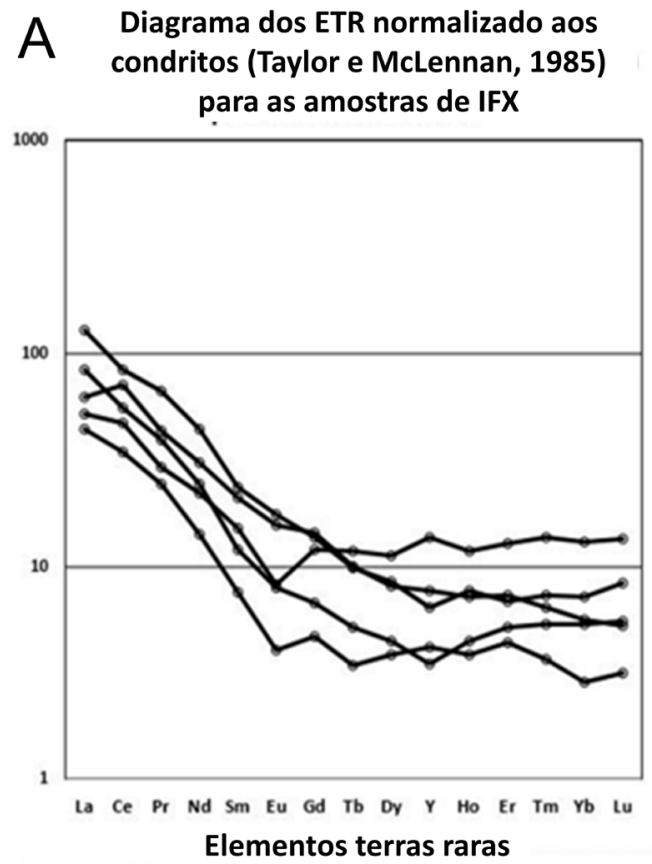

as amostras de IFX e $\left(\mathrm{Ce} / \mathrm{Ce}^{*}{ }_{(\mathrm{CN})}\right)=\left(\mathrm{Ce}_{(\mathrm{CN})} / \mathrm{La}_{(\mathrm{CN})}+\mathrm{Pr}_{(\mathrm{CN})}\right)$ $=0,343-0,418$ para as amostras de ITX.

\section{DISCUSSÃO}

\section{Elementos maiores}

As concentrações relativamente altas de $\mathrm{P}$ nas amostras de ITX são associadas à presença de apatita nos itabiritos, assim como a possível presença de goethita/limonita também sugere certa contaminação de $\mathrm{P}$ e Mn nas amostras de IFX.

O padrão dos elementos maiores (Figura 12) para as amostras de IFX e ITX da Serra do Sapo é similar aos mesmos padrões dos demais tipos de itabirito que formam o depósito (Pires e Souza, 2014; Pires e Souza et al., 2014), com exceção da presença de álcalis e altas concentrações de $\mathrm{Al}_{2} \mathrm{O}_{3}$ e $\mathrm{P}_{2} \mathrm{O}_{5}$ para ambos os tipos de itabirito. Existe também uma concentração relativamente elevada de $\mathrm{TiO}_{2}$, principalmente para as amostras de ITX em relação às amostras de IT.

\section{Elementos-traço}

O estudo da composição química das fases minerais de formações ferríferas, principalmente dos elementos-traço, é uma ferramenta importante para o entendimento da gênese dessas rochas e da contribuição das fases na composição da rocha total.

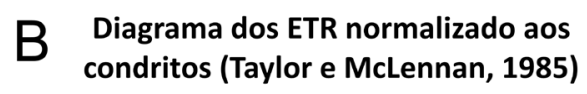
para as amostras de ITX

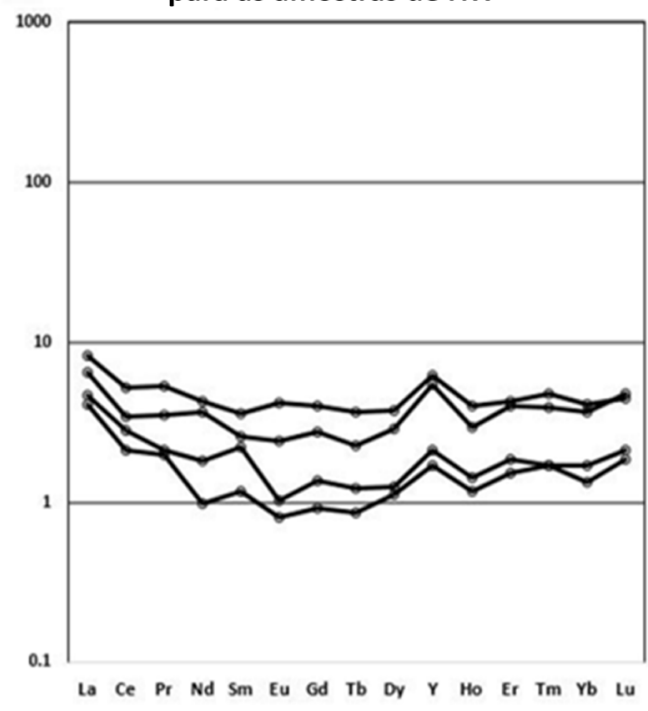

Elementos terras raras

ETR: elementos terras raras; IFX: itabirito com alto teor de contaminante; ITX: itabirito com alto teor de fósforo.

Figura 11. Elementos terras raras normalizados ao condrito. (A) Diagrama de elementos terras raras normalizados ao condrito para as amostras de itabirito com alto teor de contaminantes; (B) diagrama de elementos terras raras normalizados ao condrito para as amostras de itabirito com alto teor de fósforo. 
A abundância e a distribuição relativa dos elementos-traço, principalmente dos ETR, em rochas sedimentares é uma ferramenta poderosa para entender os ambientes geológicos e os processos ocorridos, inclusive em FFB (e.g., Frei et al., 2008).

Peter (2003) divide as concentrações dos elementos que formam as formações ferríferas em duas subdivisões, hidrotermal e detrítica. Os elementos hidrotermais são correlacionados à composição da apatita $\left(\mathrm{P}_{2} \mathrm{O}_{5}, \mathrm{Sr}\right.$ e $\left.\mathrm{CaO}\right)$, uma mistura de carbonato-sulfato-sais sulfetados $(\mathrm{Co}, \mathrm{Au}, \mathrm{S}, \mathrm{Sb}$, $\mathrm{As}, \mathrm{Mo}, \mathrm{Zn}, \mathrm{Pb}$ ). Os elementos detríticos são correlacionados às composições da clorita $(\mathrm{MgO})$ e do feldspato $(\mathrm{Ba}$, $\mathrm{K}_{2} \mathrm{O}, \mathrm{Rb}, \mathrm{Cs}$ ) e também aos elementos dos aluminossilicatos (Al, Ti, Cr, Ni, Ta, V, U, Th, Zr).

De acordo com os critérios definidos por Peter (2003), para a covariação interelementar das formações ferríferas, a concentração dos elementos-traço é relativamente mais enriquecida em $\mathrm{Rb}$, Cs e $\mathrm{Sr}$, elementos de transição, e em Mo, $\mathrm{Sb}$ eAs, elementos hidrotermais, do que em elementos detríticos. Essa correlação apenas pode ser observada para as amostras de ITX. As amostras de IFX (Figura 13) não apresentaram boa correlação entre os elementos-traço, o que pode ser explicado pelo alto grau de intemperismo dessas rochas, que são, em geral, porosas e fragmentadas, contendo uma quantidade superior de filossilicatos na sua composição.

Os gráficos para os elementos-traço foram confeccionados e comparados com os mesmos resultados obtidos para as amostras dos diferentes tipos de itabirito da Serra do Sapo descritos por Pires e Souza (2014).
As amostras de ITX FD46_05 e FD37_07 mostraram relativo enriquecimento dos elementos hidrotermais $\mathrm{Mo}, \mathrm{Zn}, \mathrm{Cu}$ $\mathrm{e} \mathrm{Pb}$ se comparadas às demais amostras de IT do depósito. A amostra FD37_08 mostra-se mais enriquecida nos elementos de transição do que as demais amostras de IT e ITX.

\section{Elementos terras raras}

Os teores dos ETR na formação ferrífera da Serra do Sapo são elevados para as amostras de IFX, podendo chegar a concentrações de 187,7 ppm e média de 23,57 ppm. Appel (1987) mostram a distribuição dos ETR relacionada com o tipo de fácies, sendo o óxido o que apresenta os valores mais baixos.

Uma característica dos ETR é a baixa solubilidade em relação aos outros elementos, e, consequentemente, menor mobilidade durante o metamorfismo de baixo grau, alterações hidrotermais e intemperismo, exceto se a razão fluído/rocha for muito elevada (Rollinson, 1993). Por esse motivo, a assinatura dos ETR em FFB pode estar relacionada com a presença desses elementos na água do mar a partir da qual o Fe foi precipitado (Bekker et al., 2010).

A análise do comportamento dos ETR nas amostras de ITX e IFX foi realizada normalizando os resultados ao PAAS e ao condrito. Há uma nítida variação no padrão de distribuição dos ETR das amostras de ITX e IFX (Figura 11). IFX mostra aumento de ETR especialmente leves em relação às amostras de ITX em razão da provável incorporação de ETR durante supergênese.

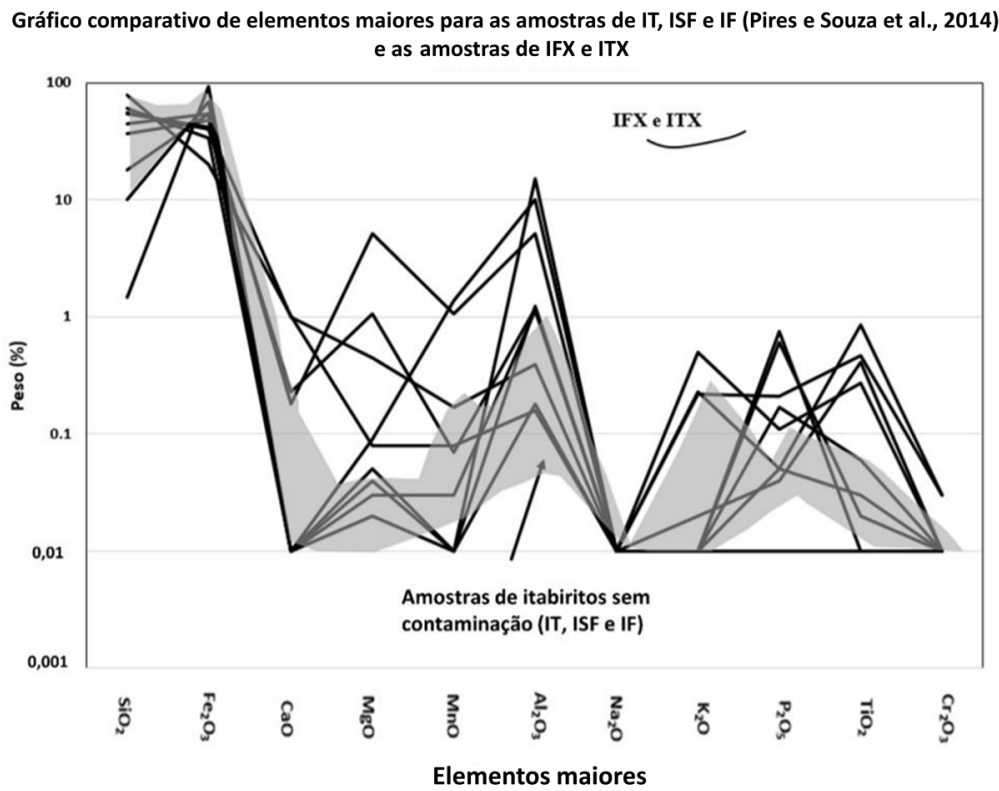

IT: itabirito; ISF: itabirito semi-friável; IF: itabirito friável; IFX: itabirito com alto teor de contaminantes; ITX: itabirito com alto teor de fósforo.

Figura 12. Comparativo de elementos maiores para as amostras de itabirito, itabirito semifriável e itabirito friável (Pires e Souza, 2014) e as amostras de formação ferrífera contaminada (itabirito com alto teor de contaminantes e itabirito com alto teor de fósforo). 
A anomalia de Ce se mostrou levemente negativa para a maioria das amostras de IT, ITX e IFX, exceto as amostras FD451_03, FD451_04, FD18_05 e FD46_09. A anomalia de Ce na água do mar é sensível à variação das condições redox e tem sido utilizada para averiguar condições subóxidas ou anóxidas da coluna d'água (Dantas, 2017).

Bau e Dulski (1996) descrevem esse comportamento como indicativo de um ambiente oxidante durante a deposição das rochas. As amostras também registram tendência para anomalias positivas em La mascarando as anomalias negativas em $\mathrm{Ce}$, o que mostra que o conteúdo de oxigênio na água do mar durante a deposição era alto suficiente para oxidar o Fe.

A anomalia de Eu para grande parte das amostras indica um leve padrão positivo, exceto as amostras FD37_07 e FD46_09. Diferentemente das anomalias positivas de Eu que indicam uma proximidade com fumarolas submarinas, as anomalias negativas indicam a deposição em posições distais das fontes hidrotermais ou fontes de temperaturas mais baixas (Neri et al., 2013).

Segundo Klein (2005), diferenças na amplitude das anomalias de Eu resultam de um declínio da contribuição hidrotermal nas bacias oceânicas do Arqueano e do Neoproterozoico. Bau e Möller (1993) atribuem essa redução à queda de temperatura das soluções hidrotermais.

O aumento dos ETRL para as amostras de IFX (Figura 10A) pode ter ocorrido durante a formação de agregados de magnetita e hematita microlamelar para formar hematita anédrica (Roy e Venkatesh, 2009). O aumento dos ETR sugere a possível presença de Fe no fluido mineralizante (Figueiredo e Silva et al., 2008). Os fluidos desempenharam papel importante na formação dos itabiritos com alto teor de $\mathrm{Fe}$ e $\mathrm{Al}$ (Brown, 2008). O minério de ferro de alto teor é o resultado da remoção sequencial e da substituição de minerais de ganga pelo processo hidrotérmico e supergênico. O IFX, assim como o IF, foi formado onde a precipitação de Fe era parcial ou ausente; a variação dos óxidos $\mathrm{MgO}, \mathrm{CaO}, \mathrm{MnO}$, $\mathrm{TiO}_{2}, \mathrm{P}_{2} \mathrm{O}_{5}$ e $\mathrm{Al}_{2} \mathrm{O}_{3}$, em alguns casos, apresentam-se diretamente proporcionais e podem indicar o processo de lixiviação e permanência de óxidos. Nesse caso, o espaço lixiviado permaneceu e o minério tornou-se muito frágil entre os níveis do bandamento. Dessa forma, o espaço intersticial geralmente é preenchido com gibbsita e/ou argilominerais. Os teores de $\mathrm{Al}_{2} \mathrm{O}_{3}$ e $\mathrm{P}_{2} \mathrm{O}_{5}$ desses litotipos estão relacionados a esse processo, assim como a presença de minerais de mica branca e sericita entre as bandas (Figuras 11 e 12).

Gutzmer et al. (2008) descrevem que os depósitos de minério com alto teor de Fe que se formaram em razão de processos supergênicos têm padrões de ETR negativamente inclinados, relativamente enriquecidos em ETRL, quando comparados às formações ferríferas menos alteradas, similar quando comparadas as amostras de ITX (Figura 10B) menos alteradas com as amostras de IFX. Além disso, ele sugere que essa pode ser uma possível maneira de distinguir depósitos de minério que se formaram em razão do enriquecimento hipogênico em relação aos depósitos formados por enriquecimento supergênico. Durante o processo

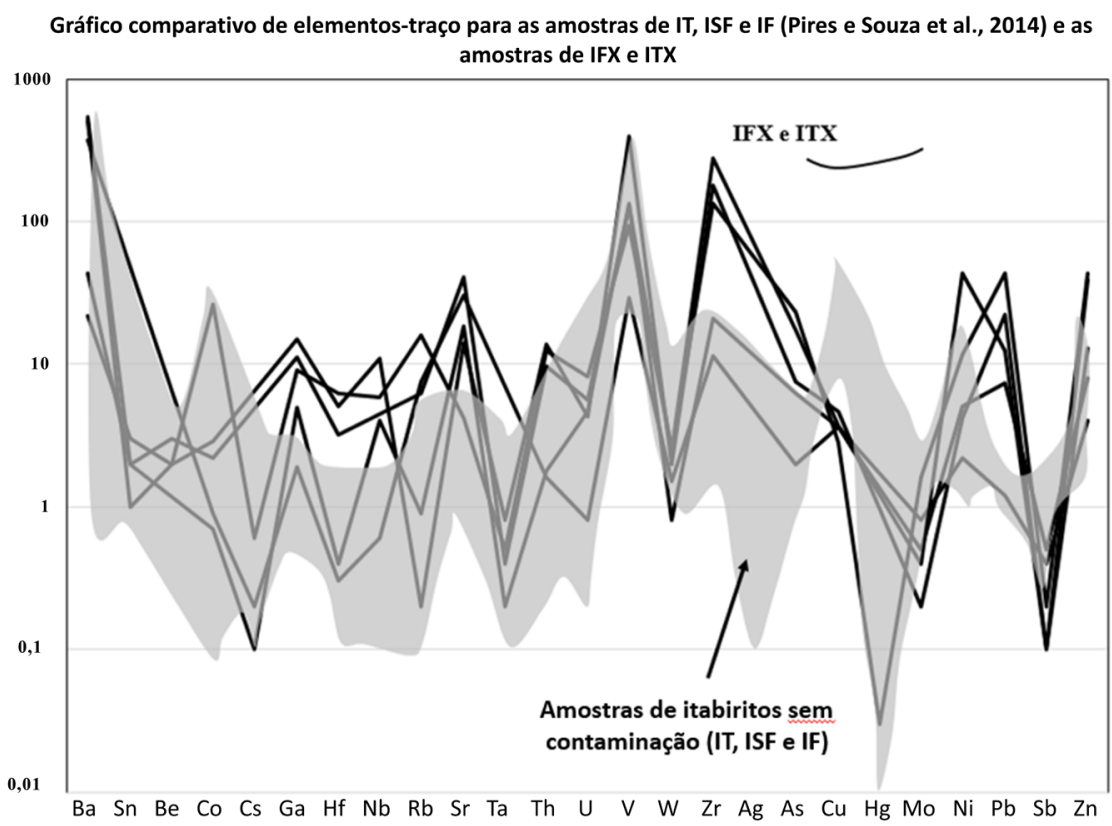

IT: itabirito; ISF: itabirito semifriável; IF: itabirito friável; IFX: itabirito com alto teor de contaminantes; ITX: itabirito com alto teor de fósforo.

Figura 13. Comparativo de elementos-traço para as amostras de itabirito, itabirito semifriável e itabirito friável (Pires e Souza, 2014) e as amostras de itabirito com alto teor de contaminantes e itabirito com alto teor de fósforo. 
de intemperismo, os ETRP têm maior mobilidade em um ambiente de baixa temperatura, resultando no enriquecimento relativo em ETRL no resíduo intemperizado.

\section{CONCLUSÕES}

As formações ferríferas da Serra do Sapo hospedam minérios classificados de acordo com o grau de intemperismo e compacidade deles. Afloramentos de IFX que ocorrem principalmente na borda leste da Serra do Sapo, no contato com os xistos da Formação Meloso, contêm teores relativamente elevados de $\mathrm{Fe}, \mathrm{Al}$ e $\mathrm{P}$.

Estudos petrográficos realizados nas amostras de IFX mostraram a presença de minerais como mica branca (muscovita, sericita), akaganeita, clorita e gibbsita como a principal fonte de Al para esse litotipo. Muscovita e gibbsita são encontradas no contato gradacional entre os xistos da Formação Meloso e os itabiritos da Formação Serra do Sapo (Figuras 6 e 7). Os altos teores de $\mathrm{Al}_{2} \mathrm{O}_{3}$ e $\mathrm{P}_{2} \mathrm{O}_{5}$ desses litotipos podem ser atribuídos à supergênese, onde o espaço dos minerais lixiviados é preenchido por argilominerais, além de outros minerais, como clorita e gibbsita. Cristais de turmalina presentes entre as fraturas dos cristais mais grossos de quartzo, e raros cristais de apatita também foram descritos, apesar de pouco abundantes se comparados às amostras de ITX.

Para o ITX, os altos teores de $\mathrm{P}$ estão relacionados à apatita que ocorre com maior frequência nesse litotipo. Clorita, muscovita, turmalina, anfibólio e zircão foram descritos como minerais acessórios. A presença dos cristais de turmalina, alinhados (Figura 6F) e intercrescidos entre as fraturas, sugere uma possível origem hidrotermal para a formação desses minerais.

Cristais de granada (Figura 6H) descritos como espessartita são acessórios nas amostras de ITX, e também são descritas em hematita compacta da região sul da Serra do Espinhaço (Almeida-Abreu et al., 1988; Almeida Abreu, 1993; Almeida-Abreu e Renger, 2002).

Entre as amostras analisadas no microscópio eletrônico também foi encontrado um mineral acessório composto principalmente de cromo (Figura 7D), podendo ser um óxido duplo de ferro e cromo, pertencente ao grupo do espinélio.

Dados geoquímicos de rocha total mostram importantes diferenças entre os tipos de minério. As amostras de IFX têm mais alto teor de $\mathrm{Fe}$ e altos teores de $\mathrm{Al} \mathrm{e}$ P. As amostras de ITX têm baixos valores de loss of ignition (LOI), refletindo seu baixo teor de elementos incompatíveis. As amostras de IFX são enriquecidas em ETR leves, o que pode refletir na mobilidade desses elementos durante o processo de enriquecimento da rocha.

O padrão ETR das amostras IFX se diferencia do conjunto de dados das amostras ITX, estando estes normalizados tanto ao PAAS quanto ao condrito. $\mathrm{O}$ grau de enriquecimento do ETRL em relação ao ETRP é apresentado na razão $\mathrm{Pr} / \mathrm{Yb}{ }_{(\mathrm{sn})}$, normalizada ao PAAS; os valores para as amostras de IFX variam de 0,398 a 1,624 , e para o ITX, de 0,170 a 0,261 . As razões das amostras de ITX mostram média de 0,219 , ficando mais próximas das razões do itabirito $(0,329)$, enquanto as razões de IFX ficaram mais longe, com média de 1,232.

As amostras de IFX enriquecidas em ETRL também são relativamente enriquecidas em elementos móveis como Ba e $\mathrm{Sr}$, e possuem maiores teores de ETR (Figura 10). Isso indica que o enriquecimento ocorre em razão da baixa mobilidade dos ETRL, em vez de enriquecimento relativo de ETRL em um ambiente intemperizado sem ETRP.

A evidência para a mobilização de ETRL é apoiada por correlações com as anomalias de $\mathrm{Ce}$ e as amostras com o mais forte enriquecimento de ETRL apresentando anomalias de Ce negativas (Figura 10B). Isso mostra que o enriquecimento observado em ETRL, Sr e Ba está associado à remobilização desses elementos durante a fase de enriquecimento supergênico. As amostras de IT e ITX são pouco alteradas intempericamente, mostrando pouco aumento em ETRL, corroborando para a própria mineralogia desses litotipos, pobres em filossilicatos e sem presença de argilominerais.

Um enriquecimento da razão Y/Ho para as amostras de ITX em relação às amostras de IFX também foi notado, podendo ser relativo ao aumento do grau de oxidação dos óxidos/hidróxidos de Fe. Isso pode evidenciar uma mudança na composição do fluido e/ou um aumento na razão rocha/fluido, favorecida pela fixação de ETR (principalmente ETRP), e uma mobilização dos elementos $\mathrm{Y}$ e Ho durante o processo de mineralização, respectivamente. A razão Y/Ho típica da água do mar fica entre $60 \mathrm{e}$ 90 , enquanto os valores para águas continentais variam de 26 a 27 (Planavsky et al., 2010). Essa diminuição da razão Y/Ho para o IFX indica uma variação do $\mathrm{Y}$ no fluido mineralizante durante a percolação e, consequentemente, a precipitação de diferentes gerações de especularita com a influência das águas continentais durante o processo supergênico.

Os valores elevados de $\mathrm{Cu}$, $\mathrm{Pb}$ e Sb para as amostras FD37_07 e FD46_05 sugerem que a formação ferrífera da Serra do Sapo teve contribuição tanto hipogênica quanto supergênica, sendo a primeira marcada por uma contribuição hidrotermal na formação de corpos hematíticos foliados e bandados podendo ou não conter altos teores de P na composição da rocha. Já o minério supergênico inclui as formações ferríferas decompostas como HM e IF.

\section{AGRADECIMENTOS}

Este trabalho foi apoiado e financiado pela Anglo American (IOB), que autorizou a publicação de dados e interpretações. Somos gratos a toda a equipe de geologia da empresa que encorajou e contribuiu para tornar este trabalho possível. Agradeço também aos meus orientadores, Rosaline Cristina Figueiredo e Silva e Carlos Alberto Rosiére, a oportunidade e os ensinamentos, e aos revisores que contribuíram para o aprimoramento deste artigo. 


\section{REFERÊNCIAS}

Almeida Abreu, P. A. (1989). Geologia das quadrículas Onça e Cuiabá (Gouveia-MG) - região meridiana central da Serra do Espinhaço Meridional. Dissertação (Mestrado). Rio de Janeiro: Departamento de Geologia, Universidade Federal do Rio de Janeiro, 75 p.

Almeida Abreu, P.A. (1993). A evolução geodinâmica da Serra do Espinhaço Meridional, Minas Gerais, Brasil. Tese (Doutorado). Freiburg Alemanha: University Freiberg, 150 p.

Almeida-Abreu, P. A., Quintão N. H., Rolim, V. K., Abreu, F. R., Magalhães, P. M. (1988). Tectônica de Nappes na Região de Ouro Fino, Conceição do Mato Dentro, MG. Revista Brasileira de Geociências, 18(2), 141-148. https:// doi.org/10.25249/0375-7536.1988182141148

Almeida-Abreu, P. A., Renger, F. E. (2002). Serra do Espinhaço Meridional: um orógeno de colisão do mesoproterozóico. Revista Brasileira de Geociências, 32(1), 1-14. https://doi. org/10.25249/0375-7536.20023210114

Appel, P. W. U. (1987). Geochemistry of the Eartly Archean Isua Iron Formation, West Greenland. In: P. W. U. Appel, G. L. LaBerge (Eds.), Precambrian Iron-Formations. Athens, Theophrastus Publications. p. 31-69.

Bau, M., Dulski, P. (1996). Distribution of yttrium and rareearth elements in the Penge and Kuruman iron- formations, Transvaal Supergroup, South Africa. Precambrian Research, 79(1-2), 37-55. https://doi.org/10.1016/0301-9268(95)00087-9

Bau, M., Möller, P. (1993). Rare earth element systematics of the chemically precipitated component in Early Precambrian iron formations and the evolution of the terrestrial atmosphere hydrosphere- lithosphere system. Geochim et Cosmochim Acta, 57(10), 2239-2249. https:// doi.org/10.1016/0016-7037(93)90566-F

Bekker, A., Slack, J. F., Planavsky, N., Krapez, B., Hofmann, A., Konhauser, K. O., Rouxel, O. J. (2010). Iron formation: The sedimentary product of a complex interplay among mantle, tectonic, oceanic, and biospheric processes. Economic Geology, 105(3), 467-508. https://doi.org/10.2113/gsecongeo.105.3.467

Brown, P. E. (2008). Brief history of high-grade iron ore mining in North America (1948-2008). Reviews in Economic Geology, 15, 361-380.

Cabral, A. R., Tupinambá, M., Lehmann, B. (2013). Spessartine in compact-hematite rock, Southern Serra do Espinhaço, Minas Gerais, and genesis of compact hematite.
Mineralogical Magazine, 77(8), 3197-3215. https://doi. org/10.1180/minmag.2013.077.8.12

Chemale Jr., F., Dussin, I. A., Alkmim, F. F., Martins, M. S., Queiroga, G., Armstrong, R., Santos, M. N. (2012). Unraveling a Proterozoic basin history through detrital zircon geochronology: The case of the Espinhaço Supergroup, Minas Gerais, Brazil. Gondwana Research, 22(1), 200-206. https://doi.org/10.1016/j.gr.2011.08.016

Chemale Jr., F., Dussin, I. A., Martins, M. S., Santos, M. N. (2011). Nova abordagem tectono-estratigráfica do Supergrupo Espinhaço em sua porção meridional (MG). Geonomos, 19(2), 173-179. https://doi.org/10.18285/geonomos.v19i2.52

Dantas, A. R. (2017). Petrografia e litoquímica de rochas ferríferas na região central do estado de Rio Grande do Norte (Domínio Rio Piranhas - Seridó, NE da Província Borborema). Dissertação (Mestrado). Natal: Centro de Ciências Exatas e da Terra - UFRN, 170 p.

Dossin, I. A., Chaves, M. L. S. C., Uhlein, A., Alvarenga, C. J. S. (1985). Geologia e depósitos diamantíferos da região de Sopa, Diamantina-MG. III Simpósio de Geologia de Minas Gerais. Anais..., v. 5, p. 276-290. Belo Horizonte: SBG/MG.

Eschwege, W. L. V. (1822). Geognostisches Gemälde von Brasilien und wahrscheinliches Muttergestein der Diamanten. Landes Industrie Comptoir, Weimar, $44 \mathrm{p}$.

Figueiredo e Silva, R. C., Lobato, L. M., Rosière, C. A., Hagemann, S., Zucchetti, M., Barrs, F. J., Morais, R., Andrade, I. (2008). A hydrotermal origin for the jaspiitehosted, giant Serra Norte iron ore deposits in the Carajas mineral province, Para State, Brazil. Reviews on Economic Geology, 15, 255-290. https://doi.org/10.5382/Rev.15.10

Frei R., Dahl P. S., Duke E. F., Frei K. M., Hansen T. R., Frandsson M. M., Jensen L. A. (2008). Trace element and isotopic characterization of Neoarchean and Paleoproterozoic iron formations in the Black Hills (South Dakota, USA): assessment of chemical change during 2.9-1.9 Ga deposition bracketing the 2.4-2.2 Ga first rise of atmospheric oxygen. Precambrian Research, 162, 441-474. https://doi. org/10.1016/j.precamres.2007.10.005

Grossi-Sad, J. H., Magalhães, J. M. M. (1989). Reconhecimento geológico do alto e médio vales do Rio Doce, Minas Gerais, Brasil. Rel. DOCEGEO/GEOSOL, 154 p. (inédito)

Gutzmer, J., Chisonga, B. C., Beukes, N. J., Mukhopadhyay, J. (2008). The geochemistry of banded iron formation-hosted 
high-grade hematite-martite iron ores. Reviews in Economic Geology, 15, 157-183. https://doi.org/10.5382/Rev.15.06

Hagemann, S. G., Rosiere, C., Gutzmer, J., Beukes, N. J. (2008). Glossary of Terms Banded Iron-Formation related high-grade iron ore. In: S. G. Hagemann, C. Rosiere, J. Gutzmer, N. Beukes (eds.), High-grade BIF-related iron mineralization. Reviews in Economic Geology, 15, 411-414.

Klein, C. (2005). Some Precambrian banded iron- formations (BIFs) from around the world: Their age, geologie, setting, mineralogy, metamorphism, geochemistry and origin. American Mineralogist, 90(10), 1473-1499. https://doi. org/10.2138/am.2005.1871

Knauer, L G. (2007). O Supergrupo Espinhaço em Minas Gerais: considerações sobre sua estratigrafia e seu arranjo estrutural. Geonomos, 15(1), 81-90.

Kullerud, G., Donnay, G., Donnay, J. D. H. (1969). Omission solid solution in magnetite: Kenotetrahedral magnetite. Zeitschrift für Kristallographie, 128(1-6), 1-17. https://doi. org/10.1524/zkri.1969.128.16.1

Lobato, L. M., Baltazar, O. F., Reis, L. B., Achtschin, A. B., Baars, F. J., Timbó, M. A., Berni, G. V., Mendonça, B. R. V, Ferreira, D. V. (2005). Projeto Geologia do Quadrilátero Ferrifero - Integração e Correção Cartográfica em SIG Nota Explicativa. Belo Horizonte, CODEMIG.

McLennan, S. M. (1989) Rare Earth Elements in Sedimentary Rocks: Influence of Provenance and Sedimentary Process. Review of Mineralogy, 21, 169-200.

Neri, M. E. V., Rosière, C. A., Lana, C. C. (2013). Supergrupo Minas na serra do Bom Sucesso, extremo sudoeste do Quadrilátero Ferrífero - MG: Petrografia, geoquímica e isótopos de U-Pb. Geologia USP. Série Cientifica, 13(2), 175-202. https://doi.org/10.5327/Z1519-874X2013000200010

Peter, J. M. (2003). Ancient iron formations: their genesis and use in the exploration for stratiform base metal sulphide deposits, with examples from the Bathurst mining camp. Geological Association of Canada, 4, 145-176.

Pires e Souza, A. A. (2014). Caracterização Mineralógica de itabiritos da Serra do Sapo, MG: Aplicação da técnica mineral liberation analyser - MLA. Dissertação (Mestrado). Belo Horizonte: Instituto de Geociências - UFMG, 121 p.

Pires e Souza, A. A., Figueiredo e Silva, R. C., Rosière, C. A., Dias, G. S., Morais, F. P. (2014). Estudos Geoquímicos de itabiritos da Serra do Sapo, Espinhaço Meridional, Minas Gerais. Geonomos, 22(2), 1-17. https://doi.org/10.18285/ geonomos.v22i2.313

Planavsky, N., Bekker, A., Rouxel, O. J., Kamber, B., Hofmann, A., Knudsen, A., Lyons, T. W. (2010). Rare Earth Element and yttrium compositions of Archean and Paleoproterozoic Fe formations revisited: New perspective on the significance and mechanisms of deposition. Geochimica et Cosmochimica Acta, 74(22), 6387-6405. https://doi. org/10.1016/j.gca.2010.07.021

Rolim, V. K. (2016). As formações ferriferas da região de Conceição do Mato Dentro - MG: Posicionamento Estratigráfico, Evolução tectônica, geocronologia, características geoquímicas e gênese dos minérios. Tese (Doutorado). Belo Horizonte: Instituto de Geociências-UFMG.

Rolim, V. K., Rosière, C. A. (2011). The Conceicão do Mato Dentro Iron Formation Province in southeastern Brazil. 11th Biennial SGA Meeting Antofagasta, Chile. Extended Abstract, 927-929.

Rolim, V. K., Rosière, C. A., Santos, J. O. S., McNaugthon, N. J. (2016). The Orosirian-Statherian banded iron formation-bearing sequences of the southern border of the Espinhaço Range, Southeast Brazil. Journal of South American Earth Science, 65, 43-66. https://doi.org/10.1016/j. jsames.2015.11.003

Rollinson, H. R. (1998). Using geochemical data: evaluation, presentation, interpretation. Singapure: Longman. 352p.

Roy, S., Venkatesh, A. S. (2009). Mineralogy and geochemistry of banded iron formation and iron ores from eastern India with implications on their genesis. Journal of Earth System Science, 118, 619-641. https://doi.org/10.1007/s12040-009-0056-Z

Santos, L. D., Brandão, P. R. G. (2002). Mineralogical, microchemical and microstructural study of brazilian iron ores. Second International Conference on the Iron Ore Industry: Today and Tomorrow (TIOITT), p. 90-103. Kiruna.

Taylor, St. R., McLennan, S. M. (1985). The Continental Crust: its Composition and Evolution. Geoscience texts. USA: Blackwell, $312 \mathrm{p}$.

Zacchi, E. N. P. (2010). Integração de dados aerogeofisicos, estruturais e geoquímicos para caracterização de formação ferrífera bandadas na região de Itapanhoacanga, $M G$. Dissertação (Mestrado). Brasília: Instituto de Geociências - UnB, 96 p. 